UNIVERSITÀ CATTOLICA DEL SACRO CUORE

Dipartimento di Economia e Finanza

\author{
Working Paper Series
}

Does fiscal decentralization affect regional disparities in health?

Quasi-experimental evidence from Italy

Cinzia Di Novi, Massimiliano Piacenza,

Silvana Robone, Gilberto Turati

Working Paper n. 83

July 2019

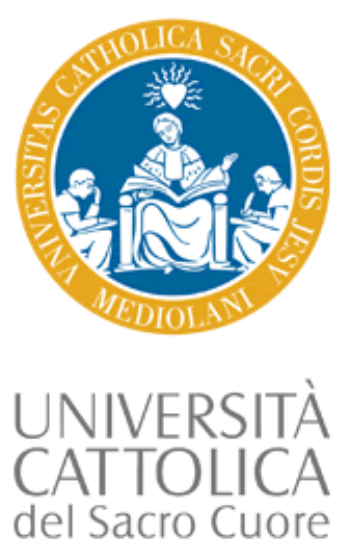




\title{
Vaccination take-up and health: evidence from a flu vaccination program for the elderly
}

\author{
Cinzia Di Novi \\ Università degli Studi di Pavia \\ Massimiliano Piacenza \\ Università degli Studi del Piemonte Orientale
}

Silvana Robone

Università degli Studi dell'Insubria

\section{Gilberto Turati}

Università Cattolica del Sacro Cuore

Working Paper n. 83

July 2019

\author{
Dipartimento di Economia e Finanza \\ Università Cattolica del Sacro Cuore \\ Largo Gemelli 1 - 20123 Milano - Italy \\ tel: +39.02.7234.2976 - fax: +39.02.7234.2781 \\ e-mail: dip.economiaefinanza@unicatt.it
}

The Working Paper Series promotes the circulation of research results produced by the members and affiliates of the Dipartimento di Economia e Finanza, with the aim of encouraging their dissemination and discussion. Results may be in a preliminary or advanced stage. The Dipartimento di Economia e Finanza is part of the Dipartimenti e Istituti di Scienze Economiche (DISCE) of the Università Cattolica del Sacro Cuore. 


\title{
Does fiscal decentralization affect regional disparities in health? \\ Quasi-experimental evidence from Italy
}

\author{
Cinzia DI NOVI * $\$$ \\ Massimiliano PIACENZA +\# § \\ Silvana ROBONE $† \varepsilon \S$ \\ Gilberto TURATI ${ }^{\circledR}$
}

\begin{abstract}
Recent theories on fiscal decentralization support the view that sub-national governments who finance a larger share of their spending with taxes raised locally by themselves are more accountable towards their citizens. Whilst evidence on improvements in spending efficiency is relatively common, little is known about the effects on inequalities amongst the population. In this paper we exploit a reform aimed at increasing regional tax autonomy in Italy to provide quasi-experimental evidence on the impact of fiscal decentralization on health disparities between- and within-regions. Our findings, robust to a number of robustness checks, support the view that fiscal decentralization does not impact on between-regional inequalities but can help to reduce inequalities within regions. However, this last effect depends on the degree of economic development: richer regions are better than poorer ones in containing inequalities.
\end{abstract}

JEL codes: H75, I14, I15, I18, R50

Keywords: fiscal decentralization, regional governments, healthcare policy, health inequalities

\footnotetext{
* University of Pavia - Dept. of Economics and Management, Via San Felice 5, 27100 Pavia, Italy. E-mail: cinzia.dinovi@unipv.it.

$\S$ Health Econometrics and Data Group (HEDG), University of York, Alcuin Building, Heslington, YO10 5DD, York, UK.

+ Corresponding Author: University of Piemonte Orientale - Dept. of Economics and Business (DISEI), Via Perrone 18, 28100 Novara, Italy. E-mail: massimiliano.piacenza@uniupo.it.

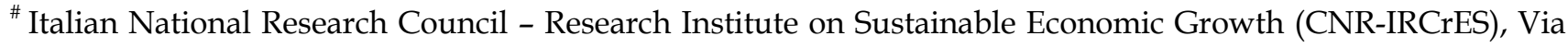
Real Collegio 30, 10024 Moncalieri (TO), Italy.

† University of Insubria - Dept. of Economics, via Monte Generoso 71, 21100 Varese, Italy. E-mail: silvana.robone@uninsubria.it.

${ }^{\varepsilon}$ Bocconi University - Dondena Centre for Research on Social Dynamics and Public Policy, via Roentgen 1, 20136 Milano, Italy

${ }^{\circ}$ Catholic University - Dept. of Economics and Finance, Largo Francesco Vito 1, 00168 Roma, Italy. E-mail: gilberto.turati@unicatt.it.
} 


\section{Introduction}

The transfer of political power and fiscal resources to sub-national tiers of government has been traditionally justified on identity grounds and heterogeneous preferences across jurisdictions (e.g., De Winter and Tursan, 1998; Oates, 1999). More recently however, a different argument has been proposed to support decentralization, namely that (fiscal) decentralization creates incentives for local officials that make them more accountable towards their citizens, hence improving the performance of their jurisdictions (e.g., Bardhan, 2002; Weingast, 2009).

While the theoretical literature is unanimous, empirical evidence is less supportive. For instance, critics point out that decentralization can lead to an increase in both the size and the number of bureaucracies (e.g., Reverte-Cejudo and Sánchez-Bayle, 1999; Repullo, 2007), and additionally to an uneven geographical distribution of benefits (e.g., Martınez-Vazquez and $\mathrm{McNab}, 2003)$. However, the empirical literature on the impact of decentralization on inequality is relatively scarce and provides mixed results (e.g., McKinnon, 1997; Qian and Weingast, 1997; Cheshire and Gordon, 1998; Shankar and Shah, 2003; Gil et al., 2004; Rodriguez-Poze and Ezcurra, 2010).

The distributional concerns become particularly apparent when considering specific policies. In this paper we concentrate on health care, and ask what are the consequences of fiscal decentralization on health disparities. The decentralization of health policy responsibilities is quite common around the world, even in unitary states (e.g., Saltman et al., 2007; Costa-Font and Greer, 2013). The central government typically devolves political authority to sub-national governments, who can then autonomously legislate on health care issues and decide how to spend monies (political and spending decentralization). But it can also assign fiscal autonomy to lower-tier governments, by granting them independent sources of revenue to finance the provision of services (fiscal decentralization).

Our focus is on the Italian National Health Service (NHS). The NHS was established in 1978, replacing the previous system based on insurance funds, with the declared goal of improving equity by providing uniform and comprehensive healthcare services across the country. However, healthcare expenditure increased steadily over time, and at the beginning of the 1990s the central government introduced reforms aimed at capping spending growth. These reforms shifted the responsibility of both managing and funding the services towards regional jurisdictions. Their declared aim was to improve spending 
efficiency by increasing regional governments' accountability via fiscal autonomy (e.g., Bordignon and Turati, 2009; Ferrario and Zanardi, 2011; Piacenza and Turati, 2014).

However, some scholars have questioned the overall welfare consequences of decentralization, which - despite improving efficiency - might have sharpened the existing differences in the access and quality of care across regions. In particular, critics point out that the richest regions could exploit substantial tax bases after devolution, and then spend more. As a consequence, between-regional inequalities might increase, and welfare in poorer regions might decrease.

But this argument fails to take into account that in Italy, as in other countries, fiscal decentralization has come together with (i) equalization grants to substantially remove differences in the tax bases, and (ii) constitutional rules defining a mandatory uniform provision of a quasi-universal set of services across the country (e.g., Costa-Font and Turati, 2017). As a consequence, following fiscal decentralization, the relative distribution of resources across regions should remain substantially stable, but the composition of funding across those same regions could change significantly. In particular, rich regions should be increasingly financed with more autonomous sources of funds ${ }^{1}$. And, according to both the theoretical and the empirical literature on fiscal federalism, the lower the share of transfers from central government sources to finance local spending, the higher will be the accountability of local officials (e.g., Weingast, 2009; Eyraud and Lusinyan, 2013).

What are the consequences on health disparities of increasing the share of local taxes to finance regional health spending? In this paper we assess the impact of fiscal decentralization of health care funding on between- and within-regional disparities in selfassessed health. We exploit a reform increasing fiscal autonomy of Italian regions since 1998 which had clear and substantial consequences on the composition of funding (e.g., Eyraud and Lusinyan, 2013, Fig. 4). The regional setting of the Italian NHS and the wide variation in the size of the tax bases offer a unique opportunity to this end. Our main finding suggests that fiscal decentralization helped contain health disparities within more fiscally autonomous regions, in a period in which within-region health inequalities were on the rise. According to our estimates, the impact on the inequality index has been on average about three times its within-region standard deviation, with much stronger effects in richer regions compared to poorer ones. This result has been obtained without any major effect on between-regional health disparities and without decreasing average perceived health.

${ }^{1}$ The gap between sub-national government' own revenue and spending identifies in the literature on fiscal federalism the Vertical Fiscal Imbalance (VFI). See, e.g., Eyraud and Lusinyan (2013). 
Our work is related to the growing literature studying the impact of decentralization on a variety of health outcomes, which provides empirical results that are often mixed and inconclusive (e.g., Jepsson and Okuonzi, 2000; Tang and Bloom, 2000; Bossert et al., 2003; Akin et al., 2005; Arreondo et al., 2005; Kolehmainen-Aitken, 2005; Saltman et al., 2007; Jimenez-Rubio, 2011; Jimenez-Rubio and Garcia-Gomez, 2017). In work considering the Italian NHS, most have focused on the relationship between decentralization and the efficiency of health policies, providing strong support to the argument that fiscal decentralization makes local governments more accountable (e.g., Bordignon and Turati, 2009; Francese et al., 2014; Piacenza and Turati, 2014; Cavalieri and Ferrante, 2016). As for the impact on inequalities, studies available so far (not only in economics) have discussed the between-regional dimension of disparities, finding mixed evidence on the impact of decentralization (e.g., De Belvis, 2012; Toth, 2014; Blöchliger et al., 2016; Costa-Font and Turati, 2017).

The remainder of this paper is organized as follows. Section 2 provides essential background information on the fiscal decentralization reform. Section 3 provides descriptive evidence on the impact of the reform on the outcome of interest. Section 4 presents the empirical strategy. Estimates are discussed in section 5, while section 6 provides brief concluding remarks.

\section{Institutional background: fiscal decentralization in Italy}

The Italian NHS is a regional system designed according to the Republican Constitution (e.g., Turati, 2014). Regional governments have the right to legislate on the organization and the supply of health care services and to allocate spending, albeit this right is limited by the legislative framework set by the central government. ${ }^{2}$ Particularly important, in this respect, is the definition of a quasi-universal set of services to be offered across all territories. This provision limits the autonomy of regional governments to enlarge the set of services publicly provided ${ }^{3}$. However, it also facilitates the comparison of access and quality of services locally supplied across different regional governments.

\footnotetext{
2 Regions are the level of government directly below the central government, and above provinces and municipalities. There are 20 regions in Italy, and they vary widely in terms of size, population, and per-capita GDP. Five of these regions historically enjoy a Special Statute, meaning they are allowed a higher degree of autonomy.

${ }^{3}$ A striking example is dental care, which is only marginally included in the set of services identified by the central government to be provided across all regions. None of the regional governments have used the available degree of fiscal autonomy to supply their citizens with this service, likely because the costs involved would be too high even for rich regions.
} 
According to independent reviewers, the Italian health care system is one of the best performers at the global level. ${ }^{4}$ However, this good performance at national level hides important differences across regions, and there is unequivocal evidence showing a deterioration in the performance of regional health care systems, moving from the North to the South of the country (e.g., Turati, 2014). For instance, the Ministry of Health carries out a yearly evaluation exercise to verify whether regional governments are effectively supplying the set of services constitutionally guaranteed. The evaluation is based on a set of indicators which are summed to obtain a final score; if the score is above a given threshold, then it is assumed that the regional governments fulfill the Constitutional mandate. Since the beginning of this exercise in 2001, most of the Southern regions have been unable to reach the minimum threshold required. ${ }^{5}$

The gradient in regional performances mirrors differences in income: the Italian Mezzogiorno - the Southern part of Italy - is poorer than the Northern part of the country. The persistently uneven distribution of income across regions had striking consequences when - during the Nineties - the central government reformed NHS funding, to match political and spending decentralization with fiscal decentralization. The main motivation behind the reform was to increase accountability at the local level (e.g., Eyraud and Lusinyan, 2013). Theory predicts that greater accountability would have been obtained by reducing transfers from the central government. In turn, more accountability would have produced an improvement in spending efficiency. To pursue this aim, following a first attempt in 1993, in 1998 the central government substituted transfers from the centre with two new autonomous sources of revenue for regions: a new regional tax on value added $(I R A P)$, and a regional surcharge on the Personal Income Tax (Addizionale Regionale IRPEF). The reason for substituting transfers with own revenues was to exploit the potential gains of decentralization while respecting the constitutional provision of uniform levels of care to be guaranteed by the central government in all regions. As transfers from the central government were cut by an amount equivalent to the increase in autonomous revenues for all regions, the reform did not modify the relative amount of resources for each region's budget for health (which increased over time), but it did change differently for different regions the composition of funding according to the tax base available in each jurisdiction.

\footnotetext{
4 See, e.g., http://www.bloomberg.com/infographics/2014-09-15/most-efficient-health-care-around-theworld.html.

5 See, e.g., the most recent official report (in Italian) published by the Ministry of Health at http://www.salute.gov.it/imgs/C_17_pubblicazioni_2245_allegato.pdf.
} 
To understand the magnitude of the impact, consider Figure 1, where we plot the share of healthcare spending financed by IRAP and IRPEF. At the national level, this share is around $40 \%$ of total spending. However, since income is unevenly distributed across regions and the tax bases of the two new regional taxes are strictly positively related to GDP, the impact of the decentralization reform on fiscal autonomy was also unequal. In Lombardy, the richest region, IRAP and IRPEF cover as much as 60\% of spending; in Calabria, the poorest region, the two new taxes fund about $10 \%$ of spending. In general, richer Northern regions experienced a larger reduction of transfers with respect to Southern regions, who continued to mostly rely on grants from the centre to fund healthcare spending. Own revenues represent about half of revenues in Centre-Northern regions, while they are just 15\% in Southern ones (e.g., Turati, 2014). As theory predicts, changes in the efficiency of health spending management were also estimated to be different across regions, with efficiency in Northern regions increasing more than in Southern ones (Bordignon and Turati, 2009; Piacenza and Turati, 2014; Cavalieri and Ferrante, 2016).

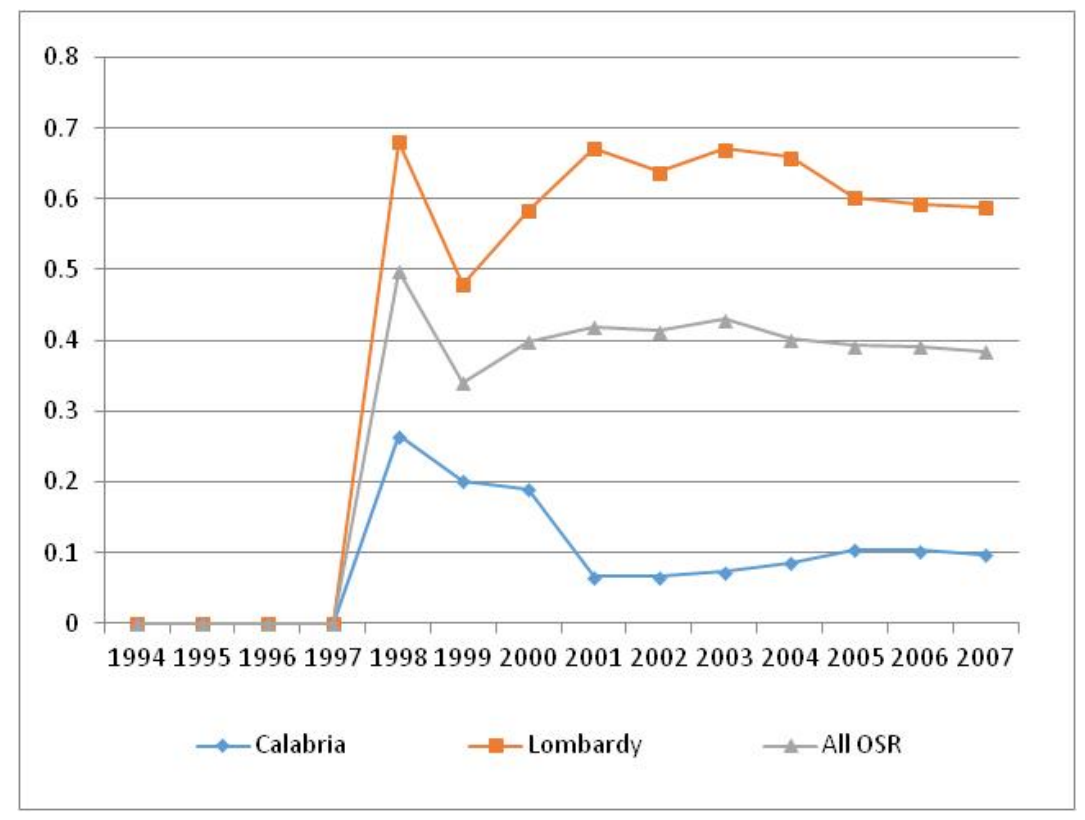

Figure 1. Share of healthcare spending financed with regional taxes

\section{Data and preliminary descriptive evidence}

In order to obtain regional measures of inequality we consider individual-level data drawn from the 1994-2007 cross-sectional Survey on the Daily Life of Italian Households (“Indagine Multiscopo sulle Famiglie - Aspetti della Vita Quotidiana") carried out yearly by the Italian 
Institute of Statistics (ISTAT). ${ }^{6}$ The survey encompasses a sample of 20,000 Italian households (60,000 individuals) living across Italy, and is representative of the whole population. ${ }^{7}$ We limit our analysis to those over 16 years old living in one of the 15 Ordinary Statute Regions. ${ }^{8}$

Self-assessed health (SAH) is our indicator for general health. SAH has been widely used in the literature examining the relationship between health, socio-economic status and lifestyles (e.g., Kenkel, 1994; Contoyannis and Jones, 2004; Balia and Jones, 2008). Moreover, SAH has been shown to be a good predictor of mortality and morbidity (e.g., Idler and Beyamini, 1997; Kennedy et al., 1998), and to have a strong correlation with more complex health and well-being indices (e.g., Unden and Elofosson, 2006). As in other similar surveys around the world, respondents are asked the following question: "Would you say that in general your health is: very bad (1), bad (2), fair (3), good (4), very good (5)". 9 SAH is clearly measured on an ordinal and categorical scale, and it requires appropriate statistical tools for the analysis.

We begin our analysis by briefly discussing the evolution of between-regional inequality. Table 1 shows some descriptive statistics on the development of SAH across all regions, before (1994-1997) and after (1998-2007) the fiscal decentralization reform. For both the median value of SAH and the percentage of individuals responding having "good" and

${ }^{6}$ Data concerning 2004 are not included in the analysis since the survey did not take place. We also do not consider data after 2007 since the incentive mechanism stemming from fiscal decentralization was substituted by centralized Recovery Plans for regional governments in deficit. Additionally, ISTAT changed the wording of the question on self-assessed health in 2008.

${ }^{7}$ As common when using individual survey data, we use survey stratification weights provided by ISTAT in all our models. Survey stratification weights are defined during survey sampling by the provider of the data and are essential to make the analysis representative of the entire population.

8 Special Statute Regions in the North and in the South have been excluded because they follow different rules and are characterized by different degrees of fiscal autonomy. Interestingly, the inclusion of these regions in the sample strengthen our main conclusions. Results obtained for the full sample of Italian regions are briefly discussed in section 5.2 and do not affect our main conclusions.

${ }^{9}$ Notice that when individuals are faced with an instrument comprising ordinal response categories, their interpretation of response categories may systematically differ across populations or populations sub-groups, also depending on their preferences and norms (Bago d'Uva et al., 2008; Rice et al., 2012). In such cases a given level of health is unlikely to be rated equally by all respondents. This phenomenon has been termed "reporting heterogeneity". In order to check that reporting heterogeneity is not a relevant issue for our analysis, we have computed the correlation between self-reported health and a more objective indicator of health, constructed through responses to fairly precise questions about specific health conditions. To build this summary measure, we use the number of health conditions reported by the respondents during the interview (heart problems, high blood pressure, high cholesterol, stroke, diabetes, lung disease, asthma, arthritis, osteoporosis, cancer, ulcer, Parkinson disease, cataracts, hip or femoral fracture, psychological problems). For each year, we run an ordered probit regression model in which the independent variable is SAH and the dependent variable is the summary indicator of health conditions. The adjusted $R^{2}$ of the model tends to be constant and equal to about $15 \%$ for all years. Hence, SAH appears as strongly predictive of the summary health index. Moreover, the results of a chi-square test shows a large and statistically significant correlation between the two variables, since, for each year, their correlation coefficients tend to be constant and equal approximately $60 \%$. 
"very good" health, we compute the mean and the coefficient of variation (CV) across regions for the two sub-periods. Neither measure shows substantial changes over time; but more importantly, the between-regional disparities in health outcomes (as measured by CV) decreased slightly. This evidence confirms the view that the tax decentralization reform has not exacerbated health disparities between regions, largely because a system of equalization grants was implemented (e.g., Costa-Font and Turati, 2017). It is also worth noting that the average per capita public health expenditure significantly increased by roughly 500 euro after the reform, while the coefficient of variation across regions slightly decreased, thus revealing also a reduction in between-regional disparities in health spending.

\begin{tabular}{lccc}
\hline Variable & $\begin{array}{c}\text { DECENTR = } \\
\text { 1994-1997 }\end{array}$ & $\begin{array}{c}\text { DECENTR = 1 } \\
\text { 1998-2007 }\end{array}$ & $\begin{array}{c}\text { t-test of the } \\
\text { difference (p-value) }\end{array}$ \\
\hline \hline Average "median SAH" & 4.533 & 4.411 & 0.002 \\
CV of "median SAH" & 0.113 & 0.107 & 0.079 \\
Average \% "good" /" very good" & 0.764 & 0.754 & 0.124 \\
CV of \% "good" /" very good" & 0.040 & 0.032 & 0.001 \\
Average of per capita public health exp. $(€)$ & 900 & 1382 & 0.006 \\
CV of per capita public health exp. & 0.099 & 0.071 & 0.005 \\
\hline
\end{tabular}

Table 1. Average and coefficient of variation (CV) across regions of health outcomes and per capita public health expenditure in the years before and after the reform

In order to provide a more detailed view of the dynamics of health outcomes across regions, Figures $2 \mathrm{a}$ and $2 \mathrm{~b}$ show the evolution of the median value of SAH and the percentage of individuals responding having "good" and "very good" health over the years from 1993 to 2007 respectively. In each figure, we present the average across all regions (green line), and the averages across the sub-samples of regions with (average) per-capita GDP below and above the sample mean value ("low-GDP" regions, red line; "high-GDP" regions, blue line). Figure 2a shows that median SAH is generally constant over time, with a very slight decrease in both the high- and low-GDP regions. In 1993, the average median SAH is 4.2 and 5 for the high-GDP and low-GDP regions respectively, while in 2007 it is 4 and 4.7 for the high-GDP and low-GDP regions respectively. Interestingly, the average median value of $\mathrm{SAH}$ in the low-GDP (high-GDP) regions is always above (below) the national average. More importantly, the distance between the low-GDP and high-GDP regions in terms of median SAH is quite stable across the time span considered, which further supports the 
view that health disparities between regions did not increase after the tax decentralization reform. A similar pattern is found for the evolution of the percentage of individuals reporting "good" and "very good" health (Figure $2 b$ ).

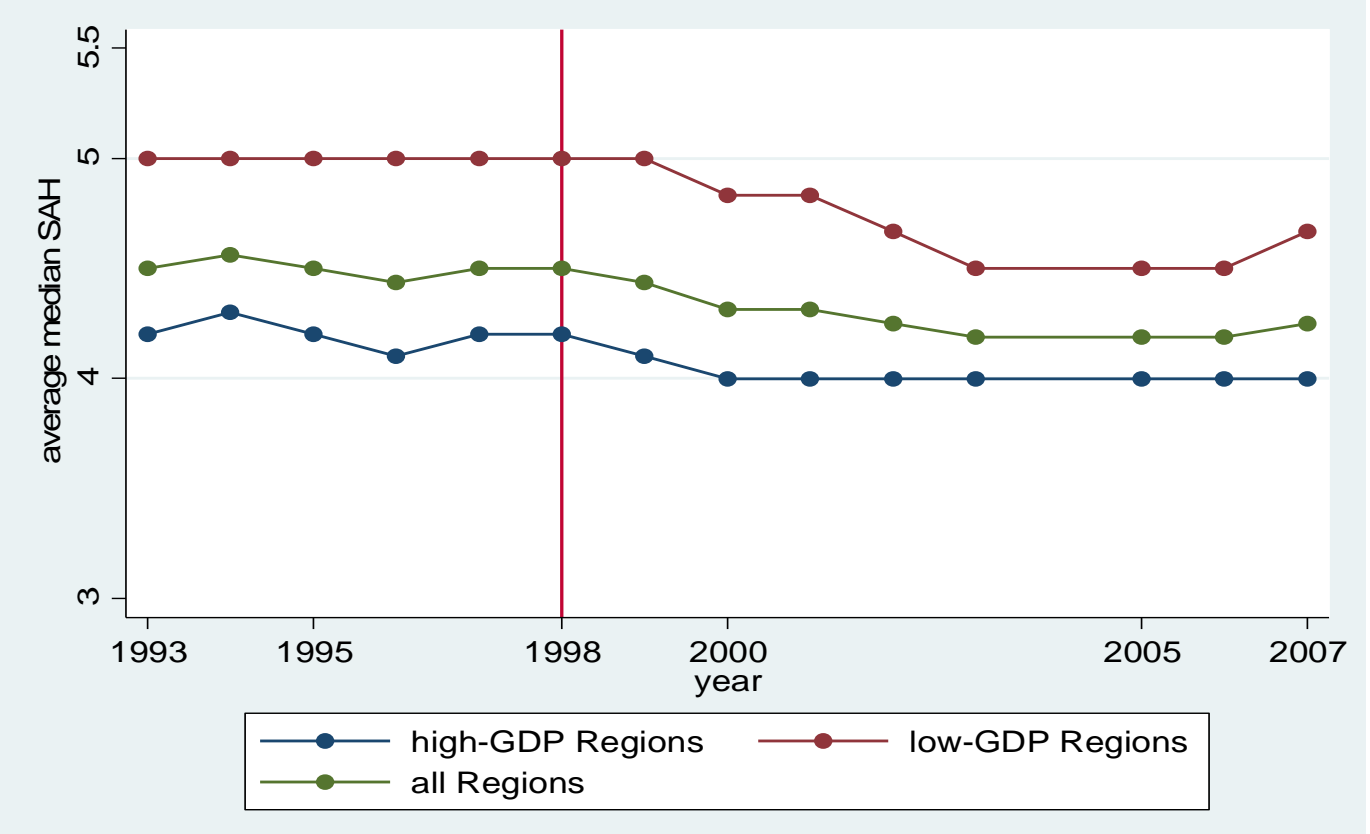

Figure 2a. Average median value of SAH, by year

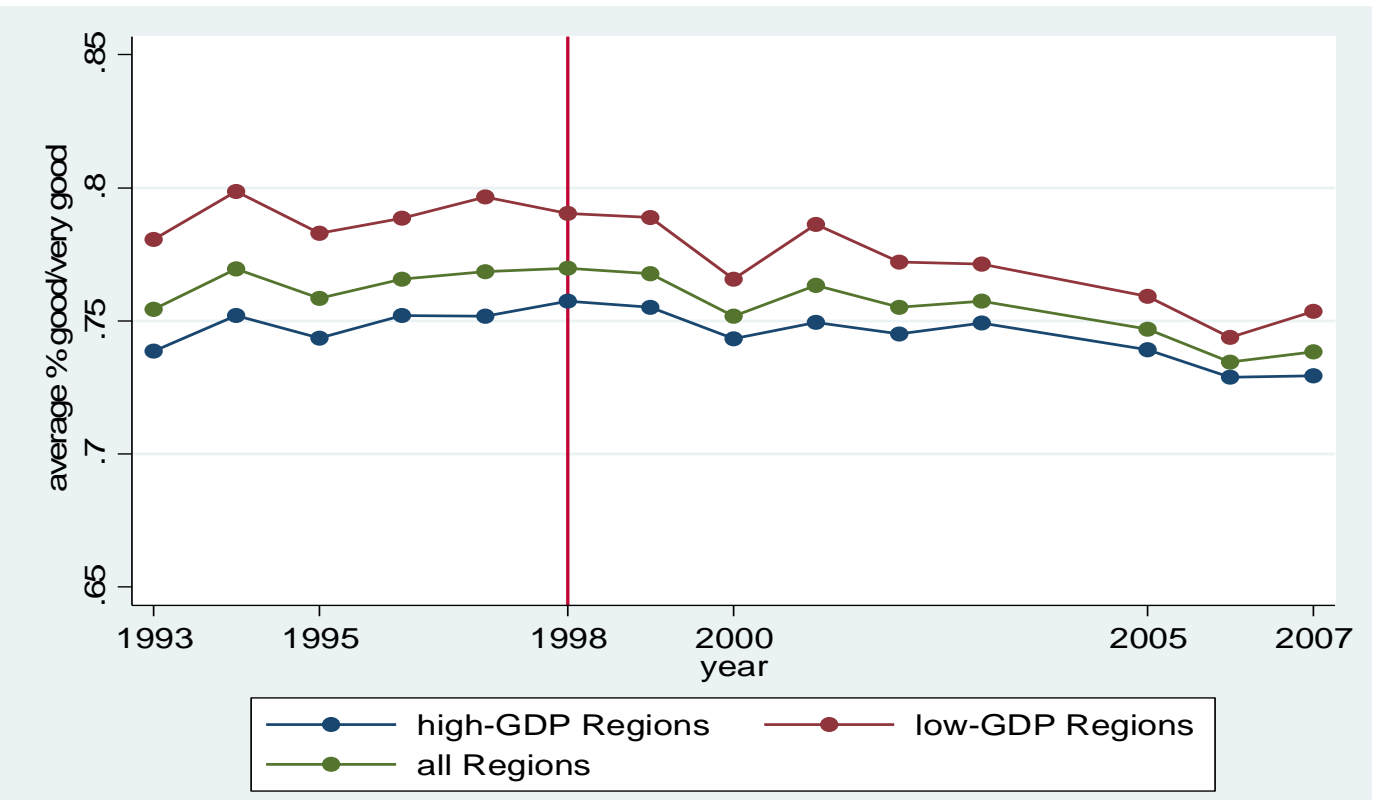

Figure $2 b$. Average $\%$ of individuals reporting "good"|"very good" health, by year

Turning now to within-regional variation in SAH, we make use of the innovative inequality index developed by Kobus and Milos (2012), a generalization of the Abul Naga and Yalcin (2008) index. The KM inequality index is "median based" (and not "mean based" as the 
more traditional inequality indexes) and lies in the interval $[0,1]$. The average value of the KM index (computed using symmetric weights for inequalities below and above the median) across regions and years is approximately 0.4 (Table 2), relatively high in comparison to other European countries studied in the still limited literature using medianbased inequality indexes. ${ }^{10}$ Figures $3 a$ and $3 b$ illustrate the evolution of the KM index over the period 1994-2007 for low-GDP regions (the less fiscally autonomous, Figure 3a) and for high-GDP regions (those more fiscally autonomous, Figure $3 b$ ). It is difficult to gauge a common pattern, but health inequalities in the first group of regions seems to increase after the fiscal decentralization reform, whereas inequality in the second group of regions appears relatively stable across the whole period.

This suggests that higher fiscal autonomy is associated with reduced inequality and we now turn our attention to identifying this relationship using a formal econometric model.

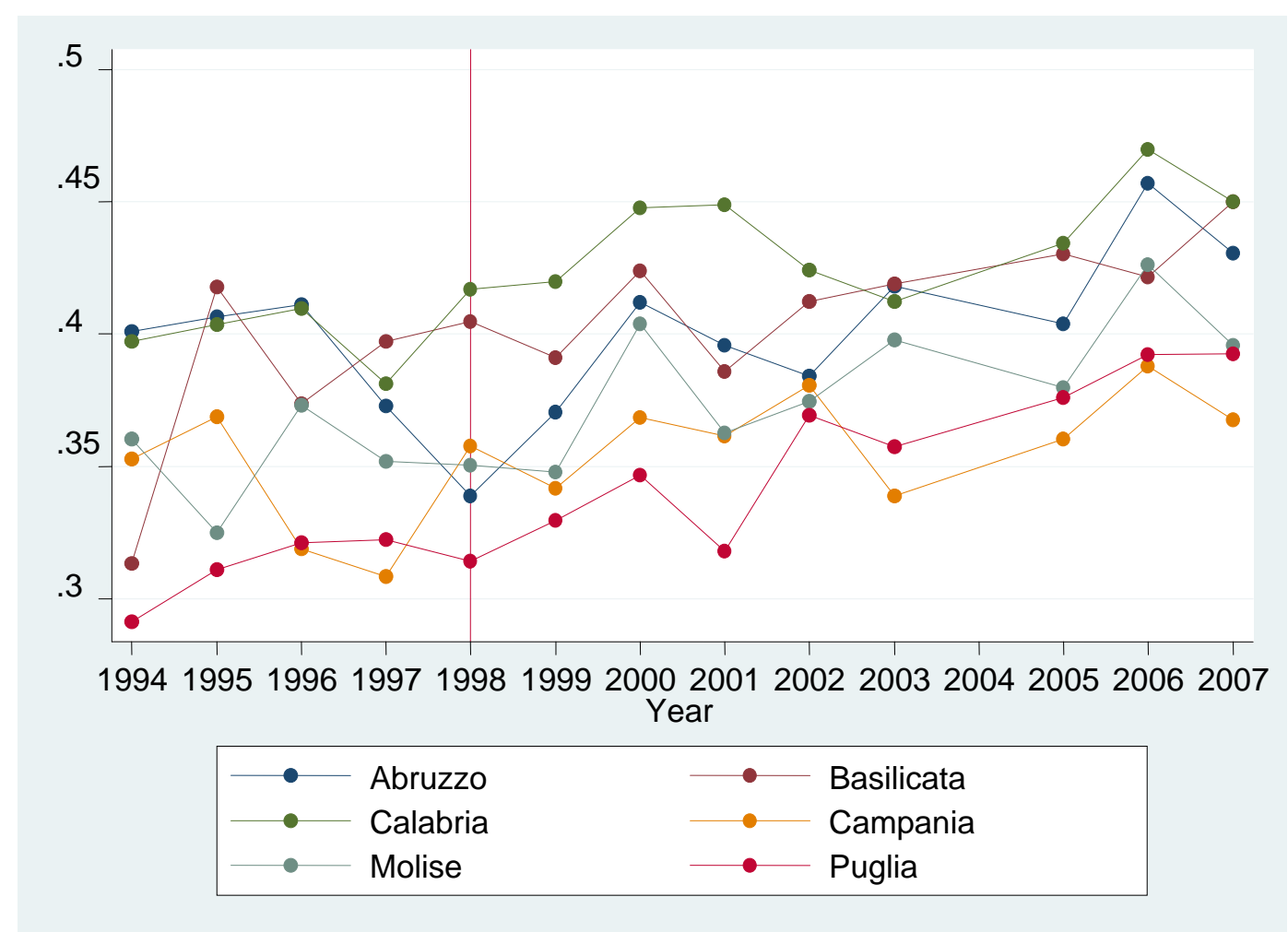

Figure 3a. KM index in regions with per-capita GDP below the mean, by region and year

\footnotetext{
${ }^{10}$ For instance, Abul Naga and Yalcin (2008) estimated an average level of inequality in self-assessed health across seven regions in Switzerland of 0.208. Madden (2010) reported an inequality index in SAH ranging from 0.356 in 2003 to 0.333 in 2006 for Ireland.
} 


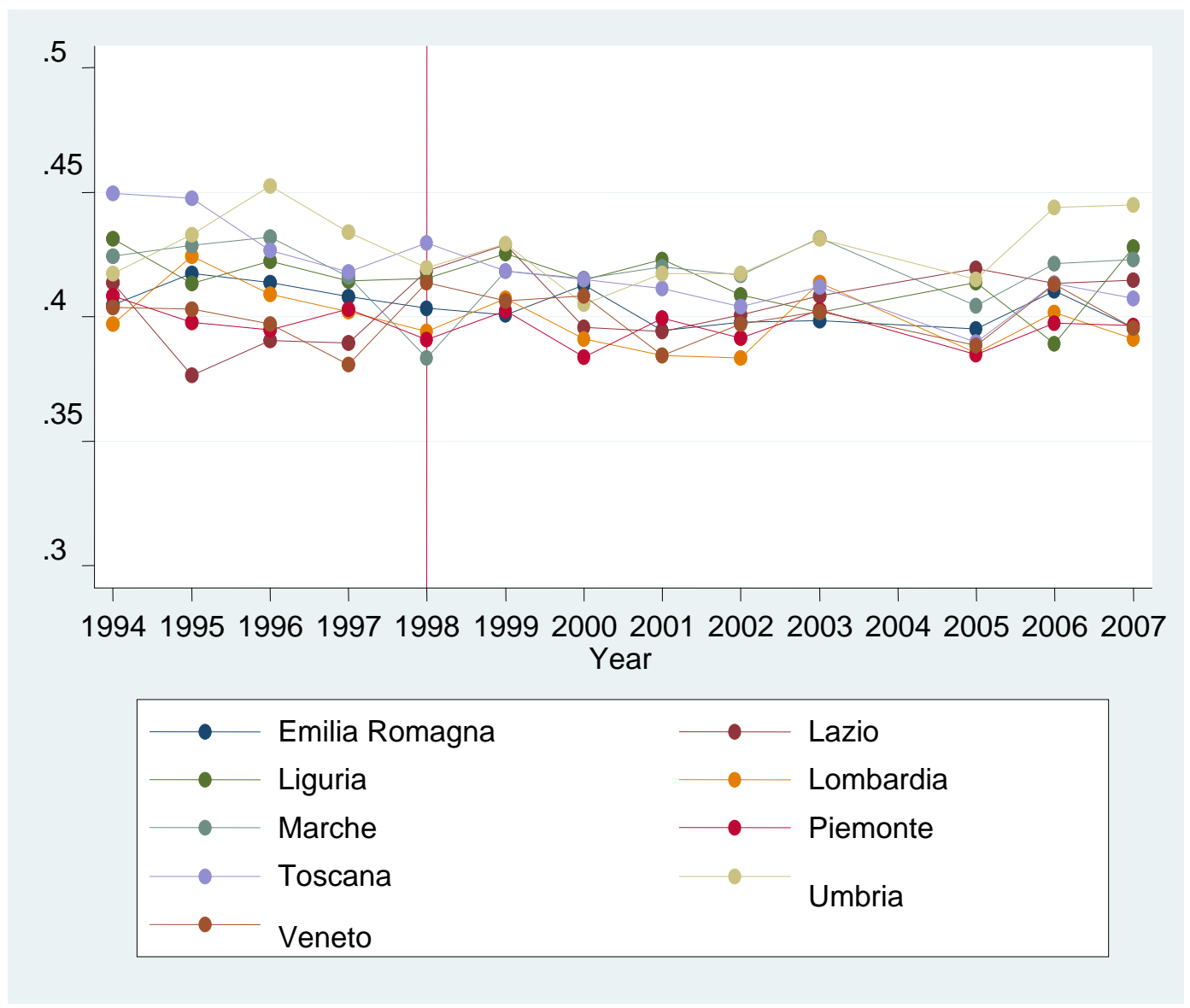

Figure 3b. KM index in regions with per-capita GDP above the mean, by region and year

\section{The empirical strategy}

\subsection{Identification}

In order to investigate the impact of the fiscal decentralization reform on within-regional health inequalities measured by the KM index, we exploit the differences in the level of income across the Italian regions. In particular, regions characterized by a higher per-capita income - hence, a higher tax base for the two new sources of own revenue - have become more fiscally autonomous than regions with a lower per-capita income (Figure 1) ${ }^{11}$. And, in turn, this would have made local politicians more accountable towards their citizens in rich regions than in poor ones. We exploit between- and within-regional variability in current GDP and adopt a multivalued treatment approach (e.g., Imbens and Wooldridge, 2009). Our general model specification is the following:

$K M_{i t}=R_{i}+T_{t}+\beta G D P_{i t} \times D E C E N T R_{t}+X_{i t}{ }^{\prime} \delta+\varepsilon_{i t}$

11 We do not consider revenues from IRAP and IRPEF since these would clearly suffer a problem of endogeneity. 
where $K M_{i t}$ is our inequality measure in Region $i$ at time $t ; R_{i}$ denotes a full set of regionspecific effects, $T_{t}$ denotes a full set of year-specific effects, $X_{i t}$ is a vector of controls, and $\varepsilon_{i t}$ is a disturbance term. Standard errors are robust, clustered at the regional level to capture potential serial correlation in the residual error term, in all estimated models.

The average causal impact of the tax decentralization reform is captured by the coefficient $\beta$ on the interaction term $G D P_{i t} \times D E C E N T R_{t}$, where $D E C E N T R_{t}$ is a dummy equal to 0 in the pre-reform period and equal to 1 from 1998 onwards. Our identification strategy relies on two assumptions. First, the degree of exposure to treatment (GDP) should be conditionally uncorrelated with the outcome variable $(K M)$. This means assuming that current GDP is orthogonal to the current level of inequality in perceived health, once controlling for time and regional fixed effects as well as a number of additional covariates. However, despite this specification, one might be worried that inequalities in health reflect inequalities in income, and that these inequalities in health are (negatively) correlated with the level of GDP. In the robustness section below we address this concern by using a pre-treatment variable as an exogenous alternative measure of the degree of exposure.

A second key assumption for the validity of our identification strategy is that the outcomes in regions differently exposed to treatment follow the same trend before the reform takes effect. As suggested by a large literature in econometrics (e.g. Angrist and Pischke, 2009), in order to test the common trend assumption, one can augment a standard difference-indifferences (DiD) regression model to include leading values of the treatment variable. If such leads were associated with the outcome variable, it would indicate that our results might be due to time trends in regions in the treatment group being systematically different from time trends in regions in the control group. The practice of including anticipatory effects in a DiD regression model to test the validity of the common trend assumption is widespread among health economics scholars (e.g. Wing et al., 2018) and may be easily accommodated in our multivalued treatment framework. ${ }^{12}$ In the analysis below, we then augment Eq. [1] with a full set of anticipatory effects (leads) of the treatment. When using this augmented specification of Eq. [1], we also consider post-treatment effects (lags) to test whether the impact of the reform was delayed over time.

Finally, a potential problem with the linear model specification we adopt is that it may not be a good representation of the data generating process for a variable assuming only values

12 For instance, this practice is adopted by Bachhuber et al. (2014) when studying the relationship between medical cannabis laws and opioid overdose mortality, and by Raifman et al. (2017) when investigating the relationship between same-sex marriage laws and adolescent suicide attempts. 
between $[0,1]$ as the $K M$ inequality index, since fitted values might stay outside the relevant interval (e.g., Wooldridge 2002). To support the robustness of our model specification, we then check whether fitted values of the inequality index from the estimated models are bounded in the interval $[0,1]$.

\subsection{Confounding factors}

Controls $X_{i t}$ in equation [1] include several confounding factors which may vary both across regions and over time. In particular, we consider two main groups of covariates: a) measures of within-regional inequality in healthcare services utilization and in lifestyles; $b$ ) regional demographic and socio-economic characteristics.

Both the use of healthcare services and lifestyles have been recognized as important determinants of inequality in health (e.g., Mackenbach, 2012, 2014). To build suitable inequality measures in these two dimensions, we exploit additional information at the individual level provided by the ISTAT Multiscopo survey. In particular, we consider four measures of inequality in services utilization: home care (inequality_home_care), emergency care (inequality_emergency_care), inpatient care (inequality_inpatient_care), and contacts with Local Health Authority to schedule appointments for outpatient visits, blood tests or other laboratory tests (inequality_contacts_LHA). All of these inequality measures are built from binary variables indicating whether or not the respondent had used any of the services during the twelve months before the interview. To account for the binary nature of these variables, we use the concentration index proposed by Erreygers (2009) to build our measures of inequality. The Erreygers index $E(y)$ corrects the standard concentration index defined by Wagstaff et al. (1991) and Wagstaff and Van Doorslaer (2000). ${ }^{13}$ The range of the Erreygers index $E(y)$ is $[-1,1]$. A negative (positive) value indicates a pro-poor (pro-rich) inequality; a value of zero indicates that healthcare access is perfectly equally distributed among the population. Since we are interested in the magnitude of need-adjusted horizontal inequality in healthcare access, we employ the absolute value of the index.

\footnotetext{
${ }^{13}$ Notice that, differently from the standard concentration index, the Erreygers index does not depend on the mean of health, healthcare and health-related behavior variables. This makes it possible to compare regions with different averages. Moreover, while the standard concentration index may give conflicting information when applied separately to health and ill-health, the Erreygers index satisfies the so called "mirror property", namely inequalities in health "mirrors" those in ill-health (Erreygers et al., 2012; Costa-Font et al., 2014). Further notice that, since straightforward numeric measures of wealth such as household income are not available in the ISTAT survey, we have to use other proxies for the household wealth. In particular, we exploit information about assets ownership and living standards collected during the interviews to build a onedimensional index of wealth using the Principal Component Analysis (PCA), under the assumption that wealth is reflected in the assets owned and in the living conditions within a household. For a detailed discussion of how to construct asset indices see Vyas and Kumaranayake (2006).
} 
Moreover, we standardize utilization considering need factors related to the individuals' health status. ${ }^{14}$

Although the role of access to healthcare services in addressing health inequality is widely recognized, there is an additional concern about growing differences in lifestyles (e.g., Costa-Font et al, 2014; Mackenbach, 2014; Vallejo-Torres et al., 2014). While there exists a substantial literature that shows that a healthier lifestyle is one of the main driving factors for good health (e.g., Contoyannis and Jones, 2004; Balia and Jones, 2008; Di Novi, 2010), little is known about the potential influence that these inequalities in lifestyles may have on health inequality. In our study we consider two measures of lifestyle differences: an index for differences in diet (inequality_diet) and an index for differences in smoking (inequality_smoke).These inequality measures are built from individual level variables provided by the ISTAT Multiscopo survey. As for diet, we use a binary variable that takes value one if the respondent does not eat breakfast nearly every day and zero otherwise. ${ }^{15}$ To measure smoking behavior we also employ a binary variable that takes value one if the respondent is currently a smoker and zero otherwise. Following Costa-Font et al. (2014), to account for the bounded nature of the health-related behavior variables (between 0 and 1), we again apply the Erreygers (2009) index. Additionally, in order to have a measure of lifestyle differences reflecting only non-demographic factors, we use the indirect method of standardization discussed above. Finally, as before, since we are interested only in the magnitude of differences in unhealthy habits, regardless of the sign (pro-poor or pro-rich), in the final regression model we include the absolute value of the two lifestyle-related indexes.

Table 2 shows that inequalities in healthcare access are pro-poor and close to zero, except for contacts with Local Health Authority to schedule appointments, which tends to be pro-

\footnotetext{
${ }^{14}$ In other words, instead of using the actual measure of healthcare access, we consider a "corrected" measure accounting for differences in needs. To this end, we start by estimating a probit model controlling for the determinants of healthcare access for each region and for each year survey. We categorize the explicative variables used to predict the demand for healthcare services into three main dimensions: need factors related to individuals' health status (age, gender, self-assessed health and health conditions), social characteristics (education and marital status), and enabling/disabling factors (private health insurance, employment status, wealth, difficulties in accessing healthcare services due to distance, monetary costs, or waiting times). We then standardize access by need factors related to individuals' health status to obtain an estimate of potentially avoidable inequality (see also O'Donnell et al., 2008). The standardisation allows for exploring whether lower socioeconomic groups are less likely to access healthcare than higher socioeconomic groups, keeping needs constant. After standardisation, any residual inequality in healthcare access is interpretable as horizontal inequity (which could be pro-rich or pro-poor).

${ }^{15}$ Belloc and Breslow (1972) in their epidemiological study based on the Alameda County survey carried out in California in 1965, found that people who eat breakfast almost every day reported better overall physical health status than breakfast skippers.
} 
rich. Looking at the dynamics of the indexes during the observed period, inequalities tend to increase over time, especially for regions with GDP per-capita below the sample mean value, which generally present greater inequality in access even when pro-poor. ${ }^{16}$ Consistent with the previous literature, differences in unhealthy lifestyles also appear to be concentrated among the poor and tend to be higher in poorer regions over time.

Demographic and socio-economic characteristics at the regional level, and summary information on regional health policies, are other important variables which may influence the inequality in health status and are included in $X_{i t}$. To control for these factors, we use data at the regional level from the ISTAT "Health for All - Italy" database. In particular, in our econometric model we control for variables capturing: (i) demographic characteristics of the regional population, namely the percentage of individuals older than 65 (population_over65) and the percentage of foreign-born residents (population_foreign); (ii) disposable income, namely the percentage of low educated individuals (population_primaryedu, the share of population with at most a primary school certificate according to ISCED classification) and the employment rate (population_employment, the share of individuals older than 15 who were employed during the year of the interview) ${ }^{17}$; (iii) the consumption rate of prescription drugs (drug_consumption, the share of individuals who consumed drugs in the two days before the interview); and (iv) the level of public health expenditure per-capita (health_spending).

Summary statistics for all variables included in the estimated models are in Table 2. Approximately $20 \%$ of the sample are over 65 , and only about $2 \%$ are foreign-born. The percentage of people with a low level of education is relatively small (about 28\%), while more than $40 \%$ of individuals were employed during the year of the interview. Approximately one in three consumed drugs within two days before the interview, and the average public health expenditure per-capita is around 1200 euro over the whole sample period.

\footnotetext{
${ }^{16}$ Descriptive statistics for inequality indexes disaggregated by years and regions are not reported for sake of brevity but are available on request.

17 These two variables will serve as proxies for private health spending, which cannot be included directly because it is likely to be endogenous.
} 


\begin{tabular}{lrrrr}
\hline Variable & Mean & Std. Dev. & Min & Max \\
\hline \hline KM index & 0.399 & 0.031 & 0.291 & 0.470 \\
GDP $(€)$ & 19,801 & 5748 & 9072 & 33,122 \\
DECENTR & 0.692 & 0.463 & 0 & 1 \\
inequality_home_care & -0.009 & 0.015 & -0.054 & 0.054 \\
inequality_emergency_care & -0.010 & 0.021 & -0.078 & 0.062 \\
inequality_contacts_LHA & 0.028 & 0.058 & -0.121 & 0.297 \\
inequality_inpatient_care & -0.012 & 0.016 & -0.054 & 0.030 \\
inequality_diet & -0.013 & 0.029 & -0.130 & 0.064 \\
inequality_smoke & -0.013 & 0.046 & -0.142 & 0.138 \\
population_over65 (\%) & 19.345 & 3.121 & 12.090 & 26.740 \\
population_foreign $(\%)$ & 2.313 & 1.815 & 0.280 & 7.590 \\
population_primaryedu $(\%)$ & 28.170 & 16.327 & 0.363 & 46.930 \\
population_employment $(\%)$ & 42.918 & 5.924 & 31.590 & 53.270 \\
drug_consumption $(\%)$ & 34.720 & 4.806 & 24.750 & 45.320 \\
health_spending $(€)$ & 1234 & 326 & 694 & 2014 \\
Nr. Observations & 195 & & & \\
\hline
\end{tabular}

Table 2. Summary statistics of the variables used in model [1]

\section{Results}

\subsection{Baseline results}

Table 3 shows the estimated impact of fiscal decentralization on within-regional health inequalities under alternative specifications of Equation [1]. All of these specifications include the set of possible confounding factors $X_{i t}$, regional fixed effects $R_{i}$, and year fixed effects $T_{t}$, to account for unobserved residual heterogeneity across regions as well as the presence of a common time trend. ${ }^{18}$ MODEL 1 refers to the baseline specification of equation [1], without any controls for possible anticipatory effects (leads) or post-treatment effects (lags). MODELS 2 to 5 test the robustness of the baseline results by including $q$ leads and $m$ lags of the treatment. More precisely, following Angrist and Pischke (2009), all the models account for three anticipatory effects $(G D P \times 1$ Year Prior $=1997, G D P \times 2$ Years Prior $=$ 1996, GDP $\times 3$ Years Prior = 1995). As for the lags, MODEL 2 includes only one post-treatment

\footnotetext{
${ }_{18}$ As anticipated in section 3, we have verified that the fitted values of the inequality index from the estimated models stay inside the interval [0.1]. This is the case for all the specifications presented in Table 3, with values ranging from 0.328 to 0.463 . Our linear model appears to be an acceptable representation of the datagenerating process.
} 
effect $(G D P \times 1$ or More Years After = 1999-2007); MODEL 3 includes two post-treatment effects $(G D P \times 1$ or More Years After $=1999$, GDP $\times 2$ or More Years After $=2000-2007)$; MODEL 4 includes three post-treatment effects $(G D P \times 1$ or More Years After $=1999, G D P \times 2$ or More Years After $=2000$, GDP $\times 3$ or More Years After $=2001-2007)$; MODEL 5 includes four posttreatment effects $(G D P \times 1$ or More Years After $=1999, G D P \times 2$ or More Years After $=2000$, GDP $\times 3$ or More Years After $=2001, G D P \times 4$ or More Years After $=2002-2007)$. Finally, in all the models GDP $\times$ Year of Adoption refers only to the effect of tax decentralization observed in 1998, when the reform was implemented.

\begin{tabular}{|c|c|c|c|c|c|c|c|c|c|}
\hline Regressors & MODEL 1 & \multicolumn{2}{|c|}{ MODEL 2} & \multicolumn{2}{|c|}{ MODEL 3} & \multicolumn{2}{|c|}{ MODEL 4} & \multicolumn{2}{|c|}{ MODEL 5} \\
\hline GDP $\times D E C E N T R$ & $-2.160^{* *} \quad(0.847)$ & - & & - & & - & & - & \\
\hline GDP $\times 3$ Years Prior & - & -3.005 & $(2.822)$ & -3.592 & $(2.820)$ & -3.490 & $(2.845)$ & -3.670 & $(2.950)$ \\
\hline$G D P \times 2$ Years Prior & - & -2.231 & $(1.941)$ & -2.963 & $(1.920)$ & -2.817 & $(1.929)$ & -3.022 & $(2.047)$ \\
\hline GDP $\times 1$ Year Prior & - & -2.091 & $(2.617)$ & -2.982 & $(2.598)$ & -2.871 & $(2.614)$ & -3.013 & $(2.707)$ \\
\hline GDP $\times$ Year of Adoption & - & -3.289 & $(2339)$ & $-4.347^{*}$ & $(2.237)$ & $-4.174^{*}$ & $(2.249)$ & $-4.409^{*}$ & $(2.357)$ \\
\hline GDP $\times 1$ or More Years After & - & $-5.059^{*}$ & $(2.453)$ & $-3.887^{*}$ & $(2.172)$ & -3.697 & $(2.201)$ & -3.996 & $(2.330)$ \\
\hline GDP $\times 2$ or More Years After & - & - & & $-7.253^{* *}$ & $(2.444)$ & $-7.623^{* * *}$ & $(2.570)$ & $-7.947^{* *}$ & $(2.730)$ \\
\hline GDP $\times 3$ or More Years After & - & - & & - & & $-6.729^{* *}$ & $(2.458)$ & $-6.429^{* *}$ & $(2.228)$ \\
\hline GDP $\times 4$ or More Years After & - & - & & - & & - & & $-7.449^{* *}$ & $(2.970)$ \\
\hline Within $\mathrm{R}^{2}$ & 0.48 & 0.49 & & 0.52 & & 0.52 & & 0.53 & \\
\hline Nr. of observations & 195 & 195 & & 195 & & 195 & & 195 & \\
\hline
\end{tabular}

Table 3. The impact of fiscal decentralization on health inequalities (a)

(a) The dependent variable is the index of inequality in self-assessed health (KM). Cluster-robust standard errors at the Region level are reported in round brackets. All models include the vector of control X, regional and year FE. MODEL 2-5 extend the baseline specification to include leads (GDP $\times 1$ Year Prior $=1997$, GDP $\times 2$ Years Prior $=1996, G D P \times 3$ Years Prior $=1995)$ and lags $(G D P \times 1$ or More Years After refers to time period 1999-2007 in MODEL 2 and only to year 1999 in MODELS 3-5; GDP $\times 2$ or More Years After refers to time period 2000-2007 in MODEL 3 and only to year 2000 in MODELS 4-5; GDP×3 or More Years After refers to time period 2001-2007 in MODEL 4 and only to year 2001 in MODEL 5; GDP $\times 4$ or More Years After refers to time period 2002-2007). GDP $\times$ Year of Adoption refers only to the effect of decentralization observed in year 1998.

** statistically significant at $5 \%$; statistically significant at $10 \%$.

The estimates in Table 3 show that the different specifications provide a consistent picture. Looking at MODEL 1, the coefficient on the interaction GDP $\times D E C E N T R$ is negative and statistically significant. Given the evolution characterizing within-regional inequality, this means that the tax decentralization reform helped contain disparities within regions. As discussed above, this result might hide differences in pre-trends and/or in post-treatment effects that are not controlled for in the baseline model. However, looking at the extended 
specifications (MODELS 2-5), coefficients for the three leads are always statistically insignificant, supporting the common trend assumption underlying our empirical strategy. In all the models except MODEL 2 the estimated coefficient for the year of adoption of the reform (GDP $\times$ Year of Adoption) is negative and statistically significant. More importantly, coefficients for the lags reveal that the magnitude of the impact increases in the years after the introduction of the reform, supporting the idea that it takes time for the reform to completely generate its effects. In particular, the impact of the reform on within-regional health inequalities is almost two times larger after two years from its adoption (coefficient for GDP $\times 2$ or More Years After) and then remains fairly constant at this new level.

The Average Treatment Effect, computed at the sample mean value of GDP in the years from 1998 to 2007, points to a reduction in KM of almost three times its within-region standard deviation, computed over the same time period. The effect clearly differs according to the exposure to the treatment, with much stronger effects in richer regions compared to poorer ones. Looking at the two extreme cases for instance, the reform caused a reduction in $K M$ which varies from about one and a half times the within standard deviation for the region with the lowest per capita GDP (Calabria, on average 14,238 euro over the period 1998-2007) to about six times the within standard deviation for the region with the highest per capita GDP (Lombardy, on average 29,272 euro). As the theory predicted, the decentralization reform had more pronounced effects in the regions that experienced a substantial increase in their fiscal autonomy; and these effects were not enough to contrast the increasing inequalities in poorer regions. This finding suggests that the increased accountability of regional governments was beneficial not only to foster efficiency, but also to avoid the deterioration of within-region inequalities.

As for the role played by the controls, results are also consistent across the different models, with most coefficients statistically insignificant. ${ }^{19}$ Of the six inequality indexes, only inequality in home care is positively correlated - as expected - with $K M$, while we do not find evidence of statistically significant effects for the remaining variables. Looking at regional characteristics, the estimates show that $K M$ increases with the consumption rate of drugs. This result might be due to the fact that the assessment of own health conditions is likely to be more heterogeneous within the group of drug consumers, in which there are both people who use drugs for minor ailments and people with serious diseases.

19 The coefficients for the whole set of controls are presented in Appendix Table A.1. 


\subsection{Robustness checks}

Our results might be influenced by different important sources of bias. First of all, as discussed in section 4.1, the use of current GDP as a measure for the degree of exposure to treatment (DECENTR) can raise endogeneity concerns; secondly, some regions might have used deficits to inflate spending in health care, and this increased spending might have influenced health outcomes as well; thirdly, a reform impacting on the financing mechanism of hospitals - which deployed its effects since 2007 - might have produced better outcomes in richer regions. We consider all of these issues in turn. As a final check, we estimate all models additionally including Special Statute Regions in our sample, and compare the results with those obtained from estimations using the original sample of Ordinary Statute Regions.

\begin{tabular}{|c|c|c|c|c|c|c|c|c|c|}
\hline Regressors & MODEL 1 & \multicolumn{2}{|c|}{ MODEL 2} & \multicolumn{2}{|c|}{ MODEL 3} & \multicolumn{2}{|c|}{ MODEL 4} & \multicolumn{2}{|c|}{ MODEL 5} \\
\hline PRE $\times D E C E N T R$ & $-2.950 * * * \quad(0.753)$ & - & & - & & - & & - & \\
\hline PRE $\times 3$ Years Prior & - & -2.611 & $(2.476)$ & -2.673 & $(2.440)$ & -2.660 & $(2.460)$ & -2.724 & $(2.503)$ \\
\hline PRE $\times 2$ Years Prior & - & -1.727 & $(1.611)$ & -1.697 & $(1.637)$ & -1.679 & $(1.651)$ & -1.717 & $(1.672)$ \\
\hline PRE $\times 1$ Year Prior & - & -1.549 & $(2.383)$ & -1.632 & $(2.333)$ & -1.675 & $(2.373)$ & -1.652 & $(2.351)$ \\
\hline PRE $\times$ Year of Adoption & - & -3.009 & $(1.996)$ & -3.022 & $(1.910)$ & -3.035 & $(1.950)$ & -3.053 & $(1.962)$ \\
\hline$P R E \times 1$ or More Years After & - & $-4.951^{\star *}$ & $(1.998)$ & -2.488 & $(1.831)$ & -2.470 & $(1.872)$ & -2.551 & $(1.899)$ \\
\hline PRE $\times 2$ or More Years After & - & - & & $-5.816^{* *}$ & $(1.997)$ & $-6.790^{* *}$ & $(2.339)$ & $-6.815^{* *}$ & $(2.345)$ \\
\hline PRE $\times 3$ or More Years After & - & - & & - & & $-5.398^{* *}$ & (1.943) & $-4.716^{* *}$ & $(1.708)$ \\
\hline PRE $\times 4$ or More Years After & - & - & & - & & - & & $-5.854^{* *}$ & $(2.317)$ \\
\hline Within $\mathrm{R}^{2}$ & 0.47 & 0.49 & & 0.51 & & 0.52 & & 0.52 & \\
\hline Nr. of observations & 195 & 195 & & 195 & & 195 & & 195 & \\
\hline
\end{tabular}

Table 4. The impact of fiscal decentralization on health inequalities controlling for the potential endogeneity of contemporaneous GDP (a)

(a) The effect of the potential endogeneity of contemporaneous GDP is tested by defining the variable PRE as the average regional GDP over the pre-reform period 1994-1997. The dependent variable is the index of inequality in self-assessed health (KM). Clusterrobust standard errors at the Region level are reported in round brackets. All models include the vector of control $\mathrm{X}$, regional and year FE. MODEL 2-5 extend the baseline specification to include leads (GDP $\times 1$ Year Prior = 1997, GDP $\times 2$ Years Prior $=1996$, GDP $\times 3$ Years Prior $=1995)$ and lags $(G D P \times 1$ or More Years After refers to time period 1999-2007 in MODEL 2 and only to year 1999 in MODELS 3-5; GDP $\times 2$ or More Years After refers to time period 2000-2007 in MODEL 3 and only to year 2000 in MODELS 4-5; GDP 3 or More Years After refers to time period 2001-2007 in MODEL 4 and only to year 2001 in MODEL 5; GDP $\times 4$ or More Years After refers to time period 2002-2007). GDP $\times$ Year of Adoption refers only to the effect of decentralization observed in year 1998.

${ }^{* *}$ statistically significant at $5 \%$; statistically significant at $10 \%$.

We address the issue of the potential endogeneity of current GDP by utilising the average of regional GDP prior to the reform. In particular, we define the variable PRE as the average 
regional GDP over the period 1994-1997. We then replace the variable GDP with the variable PRE in all models. The estimates of this new version of Eq. [1] are reported in Table 4 and largely confirm the baseline findings in terms of sign, statistical significance and magnitude of the impact of the reform, which suggests that our estimates are not biased by potential endogeneity of the treatment variable.

\begin{tabular}{|c|c|c|c|c|c|c|c|c|c|}
\hline Regressors & MODEL 1 & \multicolumn{2}{|c|}{ MODEL 2} & \multicolumn{2}{|c|}{ MODEL 3} & \multicolumn{2}{|c|}{ MODEL 4} & \multicolumn{2}{|c|}{ MODEL 5} \\
\hline$G D P \times D E C E N T R$ & $-2.207^{*} \quad(1.266)$ & - & & - & & - & & - & \\
\hline GDP $\times 3$ Years Prior & - & -4.000 & $(2.969)$ & -4.602 & $(2.954)$ & -4.526 & $(2.968)$ & -4.684 & $(3.041)$ \\
\hline GDP $\times 2$ Years Prior & - & -2.987 & $(2.253)$ & -3.682 & $(2.227)$ & -3.579 & $(2.219)$ & -3.729 & $(2.270)$ \\
\hline$G D P \times 1$ Year Prior & - & -2.271 & $(2.784)$ & -3.175 & $(2.838)$ & -3.093 & $(2.847)$ & -3.208 & $(2.887)$ \\
\hline GDP $\times$ Year of Adoption & - & -3.945 & $(2.647)$ & $-4.927^{*}$ & $(2.491)$ & $-4.789^{*}$ & $(2.483)$ & $-4.993^{*}$ & $(2.549)$ \\
\hline GDP $\times 1$ or More Years After & - & $-5.825^{*}$ & $(2.705)$ & $-4.734^{*}$ & $(2.375)$ & $-4.583^{*}$ & $(2.384)$ & $-4.844^{*}$ & $(2.457)$ \\
\hline GDP $\times 2$ or More Years After & - & - & & $-7.845^{* *}$ & $(2.691)$ & $-8.336^{* *}$ & $(2.876)$ & $-8.558^{* *}$ & $(2.941)$ \\
\hline GDP $\times 3$ or More Years After & - & - & & - & & $-7.376^{* *}$ & $(2.654)$ & $-6.831^{* *}$ & $(2.373)$ \\
\hline GDP $\times 4$ or More Years After & - & - & & - & & - & & $-8.164^{* *}$ & (3.118) \\
\hline Within $\mathrm{R}^{2}$ & 0.50 & 0.53 & & 0.55 & & 0.55 & & 0.55 & \\
\hline Nr. of observations & 169 & 169 & & 169 & & 169 & & 169 & \\
\hline
\end{tabular}

Table 5. The impact of fiscal decentralization on health inequalities excluding Regions with a high deficit in the post-reform period (a)

(a) The excluded Regions (Lazio and Campania) are those whose deficits for health spending in the period 1998-2007 summed up to more than $50 \%$ of the whole aggregated deficit computed for all Regions. The dependent variable is the index of inequality in selfassessed health $(K M)$. Cluster-robust standard errors at the Region level are reported in round brackets. All models include the vector of control X, regional and year FE. MODEL 2-5 extend the baseline specification to include leads (GDP $\times 1$ Year Prior $=1997$, GDP $\times 2$ Years Prior $=1996, G D P \times 3$ Years Prior $=1995)$ and lags $(G D P \times 1$ or More Years After refers to time period 1999-2007 in MODEL 2 and only to year 1999 in MODELS 3-5; GDP $\times 2$ or More Years After refers to time period 2000-2007 in MODEL 3 and only to year 2000 in MODELS 4-5; GDP $\times 3$ or More Years After refers to time period 2001-2007 in MODEL 4 and only to year 2001 in MODEL 5; GDP $\times 4$ or More Years After refers to time period 2002-2007). GDP $\times$ Year of Adoption refers only to the effect of decentralization observed in year 1998.

** statistically significant at $5 \%$; * statistically significant at $10 \%$.

Secondly, we consider the issue of regional deficits by considering a reduced sample which excludes Lazio and Campania, the two regions whose deficits for health spending in the period 1998-2007 (after the reform was implemented) summed up to more than 50\% of the whole aggregated deficit for healthcare in Italy (Tediosi et al., 2009). Table 5 shows the estimates of Equation [1] on this reduced sample. Our initial results are confirmed again: the tax reform caused a containment of within-regional health inequalities more pronounced in rich regions compared to poor ones; moreover, the magnitude of the impact 
increases over time and is almost double after two years of the introduction on the new regional taxes.

\begin{tabular}{l|c|cc|cc|cc|cc}
\hline Regressors & MODEL 1 & \multicolumn{2}{|c|}{ MODEL 2 } & \multicolumn{2}{|c|}{ MODEL 3 } & \multicolumn{2}{c|}{ MODEL 4 } & MODEL 5 \\
\hline \hline$G D P \times D E C E N T R$ & $-2.308^{* *}(0.908)$ & - & & - & & - & & - & \\
$G D P \times 3$ Years Prior & - & -3.055 & $(2.824)$ & -3.647 & $(2.826)$ & -3.545 & $(2.852)$ & -3.752 & $(2.967)$ \\
$G D P \times 2$ Years Prior & - & -2.273 & $(1.951)$ & -3.011 & $(1.933)$ & -2.866 & $(1.945)$ & -3.098 & $(2.075)$ \\
$G D P \times 1$ Year Prior & - & -2.429 & $(2.652)$ & -3.348 & $(2.632)$ & -3.216 & $(2.664)$ & -3.448 & $(2.809)$ \\
$G D P \times$ Year of Adoption & - & -3.682 & $(2.327)$ & $-4.773^{*}$ & $(2.249)$ & $-4.576^{*}$ & $(2.281)$ & $-4.922^{*}$ & $(2.452)$ \\
$G D P \times 1$ or More Years After & - & $-5.469^{* *}$ & $(2.549)$ & $-4.325^{*}$ & $(2.296)$ & $-4.112^{*}$ & $(2.354)$ & $-4.529^{*}$ & $(2.541)$ \\
$G D P \times 2$ or More Years After & - & - & & $-7.702^{* * *}$ & $(2.563)$ & $-8.031^{* * *}$ & $(2.641)$ & $-8.474^{* *}$ & $(2.872)$ \\
$G D P \times 3$ or More Years After & - & - & & - & & $-7.164^{* *}$ & $(2.650)$ & $-6.936^{* *}$ & $(2.444)$ \\
$G D P \times 4$ or More Years After & - & - & & - & & - & & $-8.041^{* *}$ & $(3.244)$ \\
\hline Within R & 0.48 & 0.50 & & 0.52 & & 0.53 & & 0.53 \\
Nr. Of observations & 195 & 195 & & 195 & & 195 & & 195 \\
\hline
\end{tabular}

Table 6. The impact of fiscal decentralization on health inequalities controlling also for the effect of the quasi-markets reform (a)

(a) The effect of the quasi-markets reform is tested by including in the vector of controls $X$ also a dummy variable $Q M$ equal to one when the Regions adopt their own set of DRG tariffs. The dependent variable is the index of inequality in self-assessed health (KM). Cluster-robust standard errors at the Region level are reported in round brackets. All models include the vector of control $X$, regional and year FE. MODEL 2-5 extend the baseline specification to include leads (GDP $\times 1$ Year Prior = 1997, GDP $\times 2$ Years Prior $=1996, G D P \times 3$ Years Prior $=1995)$ and lags $(G D P \times 1$ or More Years After refers to time period 1999-2007 in MODEL 2 and only to year 1999 in MODELS 3-5; GDP $\times 2$ or More Years After refers to time period 2000-2007 in MODEL 3 and only to year 2000 in MODELS 4-5; GDP $\times 3$ or More Years After refers to time period 2001-2007 in MODEL 4 and only to year 2001 in MODEL 5; GDP $\times 4$ or More Years After refers to time period 2002-2007). GDP $\times$ Year of Adoption refers only to the effect of decentralization observed in year 1998.

${ }^{* *}$ statistically significant at $5 \%$; statistically significant at $10 \%$.

We next consider the potential source of bias stemming from the quasi-market reform implemented in Italy during the Nineties. This reform, inspired by the UK experience, was aimed at improving spending efficiency (the same goal of the tax decentralization reform) working at a more micro level. In particular, it was hoped that the introduction of a new prospective payment scheme for hospitals with fixed prices based on Diagnosis Related Groups, would increase spending efficiency. The new payment system became effective in 1997, and regions were allowed to differentiate tariffs with respect to national prices. However, few regions introduced their own tariffs and those that did, did so at different times: in particular, some of the richest regions (Lombardy and Emilia Romagna) were among the first to adopt their own set of tariffs beginning in 1997, followed by Veneto in 1998. We exploit this variability across regions and years in the adoption of own tariffs to define the dummy variable $Q M$, (quasi-markets), taking value one when a region adopted a 
set of tariffs different from the national ones. Table 6 presents the estimates obtained from an augmented version of Eq. [1], which also includes the variable QM among the covariates. Our results are largely confirmed in this case, in terms of sign, magnitude and significance. Moreover, the coefficient of the variable $Q M$ is never statistically significant at the usual confidence levels, suggesting that the introduction of quasi-markets did not have any impact on inequalities. This finding is in line with Cappellari et al. (2016), who show that price incentives introduced by the quasi-markets reform did not affect perceived health. The authors argue that the quasi-market reform reduced inappropriate access to some services, with stronger effects in the first years immediately after the reform in regions that adopted their own set of tariffs.

\begin{tabular}{l|c|cc|cc|cc|cc}
\hline Regressors & MODEL 1 & \multicolumn{2}{|c|}{ MODEL 2 } & \multicolumn{2}{|c|}{ MODEL 3 } & MODEL 4 & \multicolumn{2}{c}{ MODEL 5 } \\
\hline \hline$G D P \times D E C E N T R$ & $-1.878^{* *}(0.790)$ & - & & - & & - & & - \\
$G D P \times 3$ Years Prior & - & -1.641 & $(1.966)$ & -2.086 & $(1.990)$ & -2.037 & $(2.001)$ & -2.063 & $(2.072)$ \\
$G D P \times 2$ Years Prior & - & -1.750 & $(1.608)$ & -2.349 & $(1.745)$ & -2.280 & $(1.778)$ & -2.317 & $(1.888)$ \\
$G D P \times 1$ Year Prior & - & -0.454 & $(1.935)$ & -1.192 & $(2.016)$ & -1.114 & $(2.029)$ & -1.146 & $(2.139)$ \\
$G D P \times$ Year of Adoption & - & -2.105 & $(1.801)$ & -2.954 & $(1.934)$ & -2.861 & $(1.966)$ & -2.906 & $(2.095)$ \\
$G D P \times 1$ or More Years After & - & $-3.345^{*}$ & $(1.918)$ & -2.314 & $(1.738)$ & -2.220 & $(1.763)$ & -2.278 & $(1.930)$ \\
$G D P \times 2$ or More Years After & - & - & & $-5.082^{* *}$ & $(2.246)$ & $-5.268^{* *}$ & $(2.224)$ & $-5.332^{* *}$ & $(2.408)$ \\
$G D P \times 3$ or More Years After & - & - & & - & & $-4.820^{*}$ & $(2.345)$ & $-4.740^{* *}$ & $(2.138)$ \\
$G D P \times 4$ or More Years After & - & - & & - & & - & & $-4.957^{*}$ & $(2.810)$ \\
\hline \hline Within R & 0.50 & 0.51 & & 0.52 & & 0.53 & & 0.53 \\
Nr. of observations & 247 & 247 & & 247 & & 247 & & 247 \\
\hline
\end{tabular}

Table 7. The impact of fiscal decentralization on health inequalities considering also Special Status Regions in the sample (a)

(a) The dependent variable is the index of inequality in self-assessed health $(K M)$. Cluster-robust standard errors at the Region level are reported in round brackets. All models include the vector of control X, regional and year FE. MODEL 2-5 extend the baseline specification to include leads $(G D P \times 1$ Year Prior $=1997, G D P \times 2$ Years Prior $=1996, G D P \times 3$ Years Prior $=1995)$ and lags $(G D P \times 1$ or More Years After refers to time period 1999-2007 in MODEL 2 and only to year 1999 in MODELS 3-5; GDP $\times 2$ or More Years After refers to time period 2000-2007 in MODEL 3 and only to year 2000 in MODELS 4-5; GDP $\times 3$ or More Years After refers to time period 2001-2007 in MODEL 4 and only to year 2001 in MODEL 5; GDP $\times 4$ or More Years After refers to time period 2002-2007). GDP $\times$ Year of Adoption refers only to the effect of decentralization observed in year 1998.

** statistically significant at $5 \%$; statistically significant at $10 \%$.

Finally, Table 7 reports the estimates of Eq. [1] on a larger sample which also includes the Special Statute Regions (Friuli Venezia Giulia and Trentino Alto Adige in the North, Sardinia and Sicily in the South). These regions differ markedly in terms of population and GDP per-capita, but most of all in terms of the specific fiscal relationships they maintain 
with the central government. ${ }^{20}$ Although the main conclusions of our study are still valid, all coefficients of interest are now lower in magnitude than those obtained in Table 3 . This is consistent with the fact that Special Statute Regions are largely unaffected by the fiscal decentralization reform, and thus their inclusion in the sample is expected to dilute the estimated average treatment effect.

\subsection{Discussion}

In this section we discuss some of the potential mechanisms that can explain why tax decentralization helped contain within-regional inequalities in health outcomes more in rich regions than in poor ones. The modern theories of fiscal decentralization suggest a story of incentives: local officials that need to raise more resources via own revenue are more accountable to their citizens. In turn, more accountable politicians might provide marketenhancing public goods, which positively influence economic growth at the local level; or they might offer better and more easy-to-access health care services; or they might supply more appropriate and more targeted services because of better governance. We explore each of these explanations in turn.

A first possible mechanism underlying the relationship between increased accountability of regional governments and the ability to contain health disparities may be related to regional economic growth (e.g., Akai and Sakata, 2002; Weingast, 2009). A higher degree of fiscal autonomy might have stimulated growth at the local level. A higher income, in turn, might have affected private health spending. We follow two strategies to investigate formally the validity of this argument. Firstly, we test the impact of decentralization on both per capita GDP and private health spending by estimating a model mirroring Equation [1] with a complete set of leads and lags of the treatment, where the effect of the tax reform is allowed to be different in rich and poor regions (used as the treated and control groups, respectively). In particular, we define the dummy variable $R I C H$ to identify regions with per-capita income above the sample mean, and interact this variable with DECENTR, the indicator of the post-decentralization period. As expected, for both variables we found a large difference in the trend of growth between the two groups of regions, but no evidence of any divergence caused by decentralization: per capita GDP and private health spending grew more in the North than in the South over the entire 1994-2007 period (Appendix Table

\footnotetext{
${ }^{20}$ For instance, the two autonomous provinces making up Trentino Alto Adige retain almost all the revenues they raise in their territory, receiving virtually no transfers from the central government, and also having spending autonomy on education. On the contrary, Sicily receives transfers from the central government even if it retains revenues and does not have spending autonomy on education.
} 
A.2). To confirm this finding, we also re-estimated our original models in Table 3 by substituting per capita public spending with per capita total spending for health care. Baseline results are generally unaffected when considering total spending instead of public spending (Appendix Table A.4). These results provide no evidence to support the hypothesis that the differential effect of fiscal decentralization is driven by an "income" effect.

A second possible mechanism is patient migration. Suppose that - following the reform increased accountability induced local politicians in the richest regions to provide even better services, increasing the differential in terms of quality with respect to poor regions ${ }^{21}$. Patient-inflow from poor regions would then have increased, exacerbating disparities in the Mezzogiorno among patients able to migrate to other regions (likely the richer) and those who are not (the poorer). Brekke et al. (2016) provide a similar argument in a model where regions are fully responsible for financing their healthcare systems and spending is completely funded with local resources. In particular, the authors show that, if interregional inequality increases, then we will observe an increase in the quality of services in high-income regions and an opposite effect in low income regions. Under this hypothesis, the effect in the high-income region is driven by the increase in income: quality improvements will be financed by the increase in local taxation, since the marginal cost of taxation is now lower. The improved quality will then trigger an increase in patient mobility from low-income regions. Parallel effects will be observed if intra-regional inequality in income increases.

As already observed, income inequality across regions does not play a direct role in the case of the Italian NHS, since a system of equalization grants to supply the same set of quasiuniversal services is in place. In the presence of equalization grants, an increase in interregional inequality will increase the reliance of rich-regions on their own resources, and poor regions will receive additional transfers from the center. Moreover, rich regions did not seem to have exploited fiscal autonomy given the mandatory quasi-universal set of services to be provided in all regions. However, we investigate formally the validity of patient migration as a potential explanation of our findings by considering the compensation mechanism in place in Italy to account for the free choice of patients. Suppose that a patient migrates from Region $i$ in the South to Region $j$ in the North. If this occurs, Region $i$ must compensate Region $j$ for the treatment provided to the patient paying a tariff

${ }^{21}$ We will discuss the empirical validity of this hypothesis below. 
defined at the national level. We consider total net compensations received by each region in a model including a full set of leads and lags, allowing the impact of the tax reform to be different in rich and poor regions (categorised as the treated and control groups, respectively) again using the dummy $R I C H$. The relevant coefficients are insignificant, suggesting that patients' migration cannot explain our findings (Appendix Table A.2).

This argument is further supported by an additional model designed to check whether the perceived quality of health services changed differently after the tax reform in rich and poor regions (Appendix Table A.3). If the quality differential has widened, then inequality might have increased even without any changes in the outflow of patients. However, there is no evidence of any significant differential changes in patient satisfaction for medical and nursing care, nor for the cleanliness of hospital toilets that could justify the increase in inequality in the absence of any changes in migration flows from poor to rich regions.

Finally, a third explanation is based on the idea that more accountable politicians will supply more appropriate and more targeted services, improving the governance of the regional healthcare system. In this respect, regional screening programs for cancer prevention - in particular, the malignant tumors affecting breast, colon and uterus represent an interesting policy issue to consider. For instance, breast cancer is one of the most important concerns for health in Europe because of its high incidence and mortality (e.g., Ferlay et al., 2013). Moreover, recent empirical evidence highlights that inequalities in the use of mammography are stronger in countries like Italy that does not have a national screening program; and the effectiveness of these programs in increasing preventive use is higher among the women with lower education (e.g., Carrieri and Wuebker, 2016). In general, this suggests that if - following fiscal decentralization - rich regions were more able to introduce effective screening programs, we expect to observe a higher increase of cancer prevention rates and citizens' health in these regions; and the difference with respect to poor regions should be particularly marked for less educated people. As those less educated are presumably also poorer individuals, unlikely to turn to private providers to purchase out-of-pocket screening tests, this might help explain why in Southern regions we observe a deterioration of health inequalities relative to Northern ones.

Unfortunately, we cannot directly test the effects of fiscal decentralization on cancer prevention rates, as we do not have yearly information on the adherence to screening programs in the period before and after the tax reform for individuals with different education levels. However, individual-level data from the 1994-2007 Multiscopo ISTAT 
survey (from which we defined the inequality indexes) allow us to directly test the potentially heterogeneous impact of fiscal decentralization on SAH and on the utilization of different health services across different population sub-groups in terms of education. Services are broadly defined to include home care, emergency care, inpatient care and contacts with the Local Health Authority to schedule appointments for outpatient visits, blood tests or other laboratory tests.

The estimates on sub-samples defined by the level of education (Appendix Table A.5) point to an increase in the probability of individuals with low and medium education to be healthier after the tax reform (even if the coefficient GDP $\times D E C E N T R$ is statistically significant only for the second group), and this effect is more pronounced for those living in richer regions. Moreover, following fiscal decentralization, low- and medium-educated people in richer regions scheduled more appointments with the Local Health Authority (e.g., for taking prevention tests) and accessed more home care services, while reducing more the utilization of inpatient care and emergency care services. Overall, this evidence is consistent with the hypothesis that more accountable politicians in richer regions have been able to supply more appropriate and more targeted services.

\section{Concluding remarks}

In this paper we analyze the impact of fiscal decentralization on between- and withinregional inequalities in health outcomes. To this aim, we exploit a 1998 reform implemented by the Italian government which substituted some central government transfers with two new sources of autonomous revenue for regions. Using self-reported health as an outcome, we show that fiscal decentralization did not affect between-regional inequalities but contributed to a significant containment of within-regional health inequalities. However, the magnitude of the estimated impact differs according to the level of affluence of each region, with stronger effects in rich regions compared to poor ones. The finding supports the view that the outcomes of fiscal decentralization (in terms of both efficiency and equity) depends on the level of development, which eventually determines the real degree of fiscal autonomy (e.g., Bardhan, 2002; Rodriguez-Pose and Ezcurra, 2010). Rich regions are those where a large share of spending is financed with own revenues, which favours the increase in the accountability of local politicians, who then provide more appropriate and more targeted services, improving the governance of the healthcare system. In poor regions, 
monies keep flowing from the central government, producing no effects in terms of accountability, and the governance remains weak.

Our evidence has important implications for the debate on decentralization, in Italy as in other countries. In most cases, the constitutional mandate attributing the power to manage the provision of services is common across jurisdictions, independent of their fiscal capacity. Therefore, it is hardly surprising that - following fiscal decentralization - the change in revenue composition can differ substantially across jurisdictions, as can the effect in terms of accountability. In countries where the differences are wide, one might then observe improvements in some territories, and no (or less) effects in others, as our estimates clearly show.

Where differences in fiscal capacity are wide, one should re-think decentralization, backing an institutional design of a "two-way" decentralization. For the richer regions of the country, one can decentralize spending and contemporaneously strengthen tax autonomy; eventually one can expect to obtain better outcomes, via the improved fiscal accountability following the substantial increase in autonomy. In contrast, for the less developed regions, it would be better to first implement growth-enhancing policies aimed at reducing the gap with more developed regions in terms of fiscal capacity, and only then move on to policies that target spending (and tax) decentralization. According to this view, the recipe for the Italian Mezzogiorno would be less decentralization, not more, since in these regions, fiscal decentralization will not lead to any meaningful effects in terms of accountability nor the desired improvements to services. 
Acknowledgements: We wish to thank an anonymous referee for the careful review, and the Editor Francesco Moscone for his advice. Thanks are also due to Toke Aidt, Silvia Balia, Paolo Berta, Daniel Bennett, Rinaldo Brau, Vincenzo Carrieri, Marina Cavalieri, Amitabh Chandra, Domenico De Palo, Veronica Grembi, Andrew Jones, Jens Kolbe, Rosella Levaggi, Anna Laura Mancini, Gianmaria Martini, Catia Nicodemo, Boris Nikolaev, Osea Giuntella,

Francesco Porcelli, Francesca Zantomio, and all seminar participants at the 2019 Meeting of the Society of Economics of the Household (University of Lisboa), the $30^{\text {th }}$ Conference of the Italian Society of Public Economics (University of Padova), the 6th Health Econometrics Workshop (University of Bergamo), the $3^{\text {rd }}$ Edition of the American-European Health Economics Study Group (Harvard Business School), the Bank of Italy Workshop on Local Governments (Roma, 2017), the 57 $7^{\text {th }}$ Conference of the Italian Economic Association (Bocconi University of Milan), the $27^{\text {th }}$ Conference of the Italian Society of Public Economics (University of Ferrara), the $71^{\text {st }}$ Congress of the International Institute of Public Finance (Trinity College Dublin), the $11^{\text {th }}$ World Congress of the International Health Economics Association (Bocconi University of Milan), the 2015 Meeting of the European Public Choice Society (University of Groningen), and the 19th Conference of the Italian Health Economics Association ( $\mathrm{Ca}^{\prime}$ Foscari University of Venice), for their helpful comments on preliminary drafts of this paper. Cinzia Di Novi thanks Fondazione Farmafactoring for financial support and Andrea Albarea for excellent research assistance. Massimiliano Piacenza gratefully acknowledges funding from the University of Piemonte Orientale (Bando FAR 2017). Gilberto Turati gratefully acknowledges funding from Università Cattolica del Sacro Cuore D.3.2. Strategic Research Grant “Evidence-based anti-poverty policies". The usual disclaimers apply.

\section{Declaration of interests}

We declare no competing interests.

\section{Original publication}

We declare that no prior or duplicate publication or submission elsewhere of any part of the work has been included in the manuscript.

\section{Ethics}

We declare that no ethical issues are involved in the production of this manuscript. 


\section{References}

Abul Naga R., Yalcin T. (2008) Inequality measurement for ordered response health data. Journal of Health Economics, 27: 1614-1625.

Akai N., Sakata M. (2002) Fiscal Decentralization Contributes to Economic Growth: Evidence from State-Level Cross-Section Data for the United States. Journal of Urban Economics, 52: 93-108.

Akin J., Hutchinson P., Strumpf K. (2005) Decentralisation and government provision of public goods: The public health sector in Uganda. Journal of Development Studies, 41 (8): 1417-1443.

Angrist J., Pischke J. (2009) Mostly Harmless Econometrics: An Empiricist's Companion, Princeton University Press, Princeton, NJ.

Arreondo A., Orozco E., De Icaza E. (2005) Evidences on weaknesses and strengths from health financing after decentralization: lessons from Latin American countries. International Journal of Health Planning and Management, 20 (2): 181-204.

Bachhuber M.A., Saloner B. , Cunningham C.O. , Barry C.L. (2014) Medical cannabis laws and opioidanalgesic overdose mortality in the United States, 1999-2010. JAMA Internal Medicine, 174(10): 1668-73.

Bago d'Uva, T., Van Doorslaer E., Lindeboom M., O'Donnell O. (2008) Does reporting heterogeneity bias the measurement of health disparities?. Health Economics, 17 (3): 351-375.

Balia S., Jones A.M. (2008) Mortality, lifestyle and socio-economic status. Journal of Health Economics, 27: 1-26.

Bardhan, P. (2002) Decentralization of governance and development. Journal of Economic Perspectives, 16: 185-205.

Belloc N.B., Breslow L. (1972) Relationship of physical health status and health practices. Preventive Medicine, 1: 409-421.

Blöchliger H., Bartolini D., Stossberg S. (2016) Does Fiscal Decentralisation Foster Regional Convergence?. OECD Economic Policy Paper, September 2016, No. 17.

Bordignon M., Turati G. (2009) Bailing Out Expectations and Public Health Expenditure. Journal of Health Economics, 28: 305-321.

Bossert T.J., Larrañaga O., Giedion Ú., Arbelaez J.J., Bowser D.M. (2003) Decentralization and equity of resource allocation: evidence from Colombia and Chile. Bulletin of the World Health Organization, 83 (1): 95-100.

Brekke K. R., R. Levaggi, L. Siciliani, O. R. Straume (2016) Patient mobility and health care quality when regions and patients differ in income. Journal of Health Economics, 50: 372387.

Cappellari L., De Paoli A., Turati G. (2016) Do market incentives for hospitals affect health services utilization? Evidence from prospective pay system-diagnosis related groups tariffs in Italian regions. Journal of the Royal Statistical Society - Series A, 179 (4): 885-905.

Carrieri V., Wuebker A. (2013) Assessing inequalities in preventive care use in Europe. Health Policy, 113: 247-257. 
Carrieri V., Wuebker A. (2016) Quasi-Experimental Evidence on the Effects of Health Information on Preventive Behaviour in Europe. Oxford Bulletin of Economics and Statistics, 78 (6): 765-791.

Cavalieri M., Ferrante L. (2016) Does fiscal decentralization improve health outcomes? Evidence from infant mortality in Italy. Social Science $\mathcal{E}$ Medicine, 164: 74-88.

Cheshire P. C., Gordon I. R. (1998) Territorial competition: some lessons for policy. Annals of Regional Science, 32: 321-346.

Contoyannis P., Jones A.M. (2004) Socio-economic status, health and lifestyle. Journal of Health Economics, 23: 965-995.

Costa-Font J., Greer S. (eds.) (2013) Federalism and Decentralization in European Health and Social Care, Palgrave MacMillan, London.

Costa-Font J., Hernandez-Quevedo C., Jimenez-Rubio D. (2014) Income inequalities in unhealthy life styles in England and Spain. Economics and Human Biology, 13: 66-75.

Costa-Font J., Turati G. (2017) Regional Health Care Decentralization in Unitary States: Equal Spending, Equal Satisfaction?. Regional Studies, forthcoming.

De Belvis A.T., Ferrè F., Specchia M.L., Valerio L., Fattore G., Ricciardi W. (2012) The financial crisis in Italy: Implications for the healthcare sector. Health Policy, 106: 10- 16.

De Winter L., Tursan L., (eds.) (1998) Regionalist Parties in Western Europe. London: Routledge.

Di Novi C. (2010) The influence of traffic-related pollution on individuals' life style: results from the BRFSS. Health Economics, 19: 1318-1344.

Erreygers G., (2009) Correcting the concentration index. Journal of Health Economics, 28: 504515.

Erreygers G., Clarke P., Van Ourti T. (2012), “Mirror, mirror, on the wall, who in this land is fairest of all?" - Distributional sensitivity in the measurement of socioeconomic inequality of health, Journal of Health Economics, 31(1): 257-270.

Eyraud L., Lusinyan L. (2013), Vertical fiscal imbalances and fiscal performance in advanced economies. Journal of Monetary Economics, 60 (5): 571-587.

Ferlay J., Steliarova-Foucher E., Lortet-Tieulent J., Rosso S., Coebergh J.W.W., Comber H., Forman D., Bray F. (2013). Cancer incidence and mortality patterns in Europe: estimates for 40 countries in 2012. European Journal of Cancer, 49: 1374-1403.

Ferrario C., Zanardi A. (2011) Fiscal decentralization in the Italian NHS: What happens to interregional redistribution?. Health Policy, 100 (1): 71-80.

Francese M., Piacenza M., Romanelli M., Turati G. (2014) Understanding Inappropriateness in Health Spending: The Role of Regional Policies and Institutions in Caesarean Deliveries. Regional Science and Urban Economics, 49: 262-277.

Gil C., Pascual P., Rapun M. (2004) Regional economic disparities and decentralization. Urban Studies, 41: 71-94.

Idler E.L., Benyamini Y. (1997) Self-rated health and mortality: A review of twenty-seven community studies. Journal of Health and Social Behavior, 38: 21-37.

Imbens and Wooldridge (2009) Recent Developments in the Econometrics of Program Evaluation. Journal of Economic Literature, 47 (1): 5-86. 
Jepsson A., Okuonzi S.A. (2000) Vertical or holistic decentralization of the health sector? Experiences from Zambia and Uganda. International Journal of Health Planning and Management, 15 (3): 273-289.

Jiménez-Rubio D. (2011) The impact of decentralization of health services on health outcomes: evidence from Canada. Applied economics, 43(26): 3907-3917.

Jiménez-Rubio D., Garcia-Gomez P. (2017) Decentralization of health care systems and health outcomes: Evidence from a natural experiment, Social Science \& Medicine, 188: 69-81.

Kenkel D.S. (1994) The demand for preventive medical care. Applied Economics, 26: 313-325.

Kennedy B.P., Kawachi I., Glass R., Prothrow-Stith D. (1998) Income distribution, socioeconomic status, and self rated health in the United States: Multilevel analysis. British Medical Journal, 317: 917-921.

Kobus M., Miłos P. (2012) Inequality decomposition by population subgroups for ordinal data. Journal of Health Economics, 31: 15-21.

Kolehmainen-Aitken R.L. (2004) Decentralization's impact on the health workforce: Perspectives of managers, workers and national leaders. Human Resources for Health, 2 (5).

Mackenbach J. P. (2012) The Persistence of Health Inequalities in Modern Welfare States: The Explanation of a Paradox. Social Science and Medicine, 75 (4): 761-9.

Mackenbach J. P. (2014) The Persistence of Health Inequalities in Modern Welfare States: the Role of Health Behaviors. Quarterly of the European Observatory on Health Systems and Policies, 20 (2): 6-10.

McKinnon R. (1997) Market-preserving fiscal federalism in the American Monetary Union. In M. Blejer and T. Ter-Minassian (eds) Macroeconomic Dimensions of Public Finance: Essays in Honour of Vito Tanzi, pp. 73-93, London: Routledge

Madden D. (2010) Ordinal and cardinal measures of health inequality: an empirical comparison. Health Economics, 19: 243-250.

Martınez-Vazquez J., McNab R. (2003) Fiscal decentralization and economic growth. World Development, 31: 1597-1616.

Oates W. E. (1999). An Essay on Fiscal Federalism. Journal of Economic Literature, 37(3): 11201149.

Piacenza M., Turati G. (2014) Does Fiscal Discipline towards Sub-national Governments Affect Citizens' Well-being? Evidence on Health. Health Economics, 23(2): 199-224.

Qian Y., Weingast B. (1997) Federalism as a commitment to preserving market incentives. Journal of Economic Perspectives, 11: 83-92.

Raifman J., Moscoe E., Austin B., McConnell M. (2017) Difference-in-differences analysis of the association between state same-sex marriage policies and adolescent suicide attempts. JAMA Pediatrics, 171(4): 350-56.

Repullo J. R. (2007) Gasto sanitario y descentralización: ¿saldrá a cuenta haber transferido el INSALUD?. Presupuesto y Gasto Público, 49: 47-66.

Reverte-Cejudo D., Sánchez-Bayle M. (1999) Devolving health services to Spain's autonomous regions. British Medical Journal, 318 (7192): 1204-1205. 
Rice N., Robone S., Smith P.C. (2012) Vignettes and health systems responsiveness in crosscountry comparative analyses. The Journal of The Royal Statistical Society, Series A., 175 337-369.

Rodriguez-Pose A., Ezcurra R. (2010) Does decentralization matter for regional disparities? A cross-country analysis. Journal of Economic Geography, 10: 619-644.

Saltman R.B., Bankauskaite V., Vrangbæk K. (eds.) (2007) Decentralization in health care, Maidenhead: McGraw-Hill

Shankar R., Shah A. (2003) Bridging the economic divide within countries: a scorecard on the performance of regional policies in reducing regional income disparities. World Development, 31: 1421-1441.

Tang S., Bloom G. (2000) Decentralizing rural health services: a case study in China. International Journal of Health Planning and Management, 15 (3): 189-200.

Tediosi F., Gabriele S., Longo F. (2009), Governing decentralization in health care under tough budget constraint: What can we learn from the Italian experience? Health Policy, 90: 303-312.

Toth F. (2014) How health care regionalization in Italy is widening the North-South gap. Health Economics, Policy and Law, 9 (3): 231-249.

Turati G. (2014) The Italian Servizio Sanitario Nazionale: A Renewing Tale of Lost Promises. In: Costa-Font J. and Greer S. (eds.), Federalism and Decentralization in European Health and Social Care, Palgrave MacMillan, London.

Undén A.L., Elofsson S. (2006) Do different factors explain self-rated health in men and women?. Gender Medicine, 3(4): 295-308.

Vallejo-Torres L., Hale D., Morris S., et al. (2014) Income-related inequality in health and health-related behaviour: exploring the equalisation hypothesis. Journal of Epidemiologic Community Health, Published Online First: [March 11, 2014] doi:10.1136/jech-2013-203306.

Vyas S., Kumaranayake L. (2006) Constructing socio-economic status indices: how to use principal components analysis. Health Policy and Planning, 21 (6): 459-468.

Wagstaff A., Paci P., van Doorslaer E. (1991), On the measurement of inequalities in health. Social Science E Medicine, 33 (5): 545-557.

Wagstaff A., Van Doorslaer E. (2000) Measuring and Testing for Inequity in the Delivery of Health Care. Journal of Human Resources, 35(4): 716-33.

Weingast B.R. (2009) Second Generation Fiscal Federalism: the implication of fiscal incentives. Journal of Urban Economics, 65: 279-293.

Wing C., Simon K., Bello-Gomez R.A. (2018) Designing Difference in Difference Studies: Best Practices for Public Health Policy Research. Annual Review of Public Health, 39: 453-69. 


\section{APPENDIX}

\begin{tabular}{|c|c|c|c|c|c|c|c|c|c|c|}
\hline Regressors & \multicolumn{2}{|c|}{ MODEL 1} & \multicolumn{2}{|c|}{ MODEL 2} & \multicolumn{2}{|c|}{ MODEL 3} & \multicolumn{2}{|c|}{ MODEL 4} & \multicolumn{2}{|c|}{ MODEL 5} \\
\hline$G D P \times D E C E N T R$ & $-2.160^{* *}$ & $(0.847)$ & - & & - & & - & & - & \\
\hline$G D P \times 3$ Years Prior & - & & -3.005 & $(2.822)$ & -3.592 & $(2.820)$ & -3.490 & $(2.845)$ & -3.670 & $(2.950)$ \\
\hline$G D P \times 2$ Years Prior & - & & -2.231 & $(1.941)$ & -2.963 & $(1.920)$ & -2.817 & $(1.929)$ & -3.022 & $(2.047)$ \\
\hline GDP $\times 1$ Year Prior & - & & -2.091 & $(2.617)$ & -2.982 & $(2.598)$ & -2.871 & $(2.614)$ & -3.013 & $(2.707)$ \\
\hline GDP $\times$ Year of Adoption & - & & -3.289 & $(2339)$ & $-4.347^{*}$ & $(2.237)$ & $-4.174^{*}$ & $(2.249)$ & $-4.409^{*}$ & $(2.357)$ \\
\hline GDP $\times 1$ or More Years After & - & & $-5.059^{*}$ & (2.453) & $-3.887^{*}$ & $(2.172)$ & -3.697 & $(2.201)$ & -3.996 & $(2.330)$ \\
\hline GDP $\times 2$ or More Years After & - & & - & & $-7.253^{* *}$ & $(2.444)$ & $-7.623^{* * *}$ & $(2.570)$ & $-7.947^{* *}$ & $(2.730)$ \\
\hline GDP $\times 3$ or More Years After & - & & - & & - & & $-6.729^{* *}$ & $(2.458)$ & $-6.429^{* *}$ & $(2.228)$ \\
\hline GDP $\times 4$ or More Years After & - & & - & & - & & - & & $-7.449^{* *}$ & $(2.970)$ \\
\hline inequality_home_care & $0,171^{* *}$ & $(0,070)$ & $0,200^{* *}$ & $(0,077)$ & $0,183^{* *}$ & $(0,078)$ & $0,184^{* *}$ & $(0,077)$ & $0,193^{* *}$ & $(0,078)$ \\
\hline inequality_emergency_care & $-0,005$ & $(0,078)$ & 0,024 & $(0,097)$ & 0,061 & $(0,092)$ & 0,061 & $(0,091)$ & 0,070 & $(0,090)$ \\
\hline inequality_contacts_LHA & $-0,017$ & $(0,037)$ & $-0,013$ & $(0,034)$ & $-0,009$ & $(0,032)$ & $-0,011$ & $(0,033)$ & $-0,006$ & $(0,035)$ \\
\hline inequality_inpatient_care & 0,029 & $(0,095)$ & 0,027 & $(0,096)$ & 0,029 & $(0,099)$ & 0,021 & $(0,101)$ & 0,034 & $(0,099)$ \\
\hline inequality_diet & $-0,031$ & $(0,088)$ & $-0,026$ & $(0,088)$ & $-0,063$ & $(0,086)$ & $-0,067$ & $(0,088)$ & $-0,049$ & $(0,085)$ \\
\hline inequality_smoke & 0,063 & $(0,047)$ & 0,069 & $(0,055)$ & 0,057 & $(0,057)$ & 0,059 & $(0,058)$ & 0,058 & $(0,057)$ \\
\hline population_over65 & 0,005 & $(0,009)$ & 0,004 & $(0,008)$ & 0,004 & $(0,008)$ & 0,003 & $(0,007)$ & 0,004 & $(0,007)$ \\
\hline population_foreign & $-0,006$ & $(0,004)$ & $-0,005$ & $(0,003)$ & $-0,004$ & $(0,003)$ & $-0,005$ & $(0,003)$ & $-0,004$ & $(0,003)$ \\
\hline population_primaryedu & $-0,001$ & $(0,001)$ & $-0,001$ & $(0,001)$ & $-0,001$ & $(0,001)$ & $-0,001$ & $(0,001)$ & $-0,001$ & $(0,001)$ \\
\hline population_employment & $-0,001$ & $(0,001)$ & $-0,001$ & $(0,001)$ & $-0,001$ & $(0,001)$ & $-0,001$ & $(0,001)$ & $-0,001$ & $(0,001)$ \\
\hline drug_consumption & $0,002^{*}$ & $(0,001)$ & $0,002^{*}$ & $(0,001)$ & $0,002^{*}$ & $(0,001)$ & $0,002^{*}$ & $(0,001)$ & $0,002^{*}$ & $(0,001)$ \\
\hline health_spending & 0,000 & $(0,000)$ & 0,000 & $(0,000)$ & 0,000 & $(0,000)$ & 0,000 & $(0,000)$ & 0,000 & $(0,000)$ \\
\hline Within $\mathrm{R}^{2}$ & 0.48 & & 0.49 & & 0.52 & & 0.52 & & 0.53 & \\
\hline Nr. of observations & 195 & & 195 & & 195 & & 195 & & 195 & \\
\hline
\end{tabular}

\section{Appendix Table A.1. The impact of fiscal decentralization on health inequalities (estimated coefficients of control variables included) (a)}

(a) The dependent variable is the index of inequality in self-assessed health $(K M)$. Cluster-robust standard errors at the Region level are reported in round brackets. All models include the vector of control X, regional and year FE. MODEL 2-5 extend the baseline specification to include leads (GDP $\times 1$ Year Prior $=1997, G D P \times 2$ Years Prior $=1996, G D P \times 3$ Years Prior $=1995)$ and lags $(G D P \times 1$ or More Years After refers to time period 1999-2007 in MODEL 2 and only to year 1999 in MODELS 3-5; GDP $\times 2$ or More Years After refers to time period 2000-2007 in MODEL 3 and only to year 2000 in MODELS 4-5; GDP $\times 3$ or More Years After refers to time period 2001-2007 in MODEL 4 and only to year 2001 in MODEL 5; GDP $\times 4$ or More Years After refers to time period 2002-2007). GDP $\times$ Year of Adoption refers only to the effect of decentralization observed in year 1998.

** statistically significant at $5 \%$; statistically significant at $10 \%$. 


\begin{tabular}{|c|c|c|c|c|c|c|}
\hline \multirow[b]{2}{*}{ RICH $\times 3$ Years Prior } & \multicolumn{2}{|c|}{$\begin{array}{l}\text { per-capita } \\
\text { GDP }\end{array}$} & \multicolumn{2}{|c|}{$\begin{array}{c}\text { per-capita } \\
\text { private health spending }\end{array}$} & \multicolumn{2}{|c|}{$\begin{array}{l}\text { cross-regional } \\
\text { patient mobility }\end{array}$} \\
\hline & $693.034^{* * *}$ & $(115.422)$ & $8.859^{* * *}$ & $(2.519)$ & -68.989 & $(87.264)$ \\
\hline RICH $\times 2$ Years Prior & $1135.890^{* * *}$ & (199.197) & $27.040^{* * *}$ & $(3.521)$ & -84.881 & $(44.946)$ \\
\hline RICH $\times 1$ Year Prior & $1324.592^{* * *}$ & $(243.596)$ & $45.269^{* * *}$ & $(6.045)$ & -1.848 & $(15.052)$ \\
\hline RICH $\times$ Year of Adoption & $1667.697^{* * *}$ & $(235.290)$ & $55.450^{\star * *}$ & $(8.224)$ & -7.637 & $(20.757)$ \\
\hline RICH $\times 1$ Year After & $1829.779 * * *$ & $(225.097)$ & $57.508^{* * *}$ & $(8.281)$ & 18.113 & $(24.591)$ \\
\hline RICH $\times 2$ Years After & $2585.038^{* * *}$ & $(404.132)$ & $74.315^{* * *}$ & $(12.253)$ & -3.705 & $(13.635)$ \\
\hline RICH $\times 3$ Years After & $2944.872^{* * *}$ & $(398.671)$ & $73.634^{* * *}$ & $(11.646)$ & -35.205 & $(30.642)$ \\
\hline RICH $\times 4$ or More Years After & $3692.900^{* * *}$ & $(466.159)$ & $77.744^{* * *}$ & $(15.786)$ & 45.211 & $(48.693)$ \\
\hline Within $\mathrm{R}^{2}$ & 0.98 & & 0.95 & & 0.17 & \\
\hline Nr. of observations & 195 & & 195 & & 195 & \\
\hline
\end{tabular}

\section{Appendix Table A.2. The impact of fiscal decentralization on regional per-capita GDP, private health spending, and cross-regional patient mobility (a)}

(a) Cluster-robust standard errors at the Region level are reported in round brackets. RICH is a dummy variable equal to 1 for regions with average per-capita income above the sample mean value (treated group) and 0 for those with income below the sample mean value (control group). All models include regional and year FE. All estimated models consider leads $($ RICH $\times 3$ Years Prior = 1995, RICH $\times 2$ Years Prior = 1996, RICH $\times 1$ Year Prior = 1997) and lags $(R I C H \times 1$ Year After = 1999; RICH $\times 2$ Years After $=2000 ;$ RICH $\times 3$ Years After $=2001 ; R I C H \times 4$ or More Years After refers to years 2002-2007). RICH $\times$ Year of Adoption refers to the effect of fiscal decentralization observed in year 1998.

*** statistically significant at $1 \%$; ** statistically significant at $5 \%$; * statistically significant at $10 \%$. 


\begin{tabular}{|c|c|c|c|c|c|c|}
\hline \multirow[b]{2}{*}{ RICH $\times 1$ Year After } & \multicolumn{2}{|c|}{$\begin{array}{l}\text { Satisfaction for } \\
\text { medical care }\end{array}$} & \multicolumn{2}{|c|}{$\begin{array}{l}\text { Satisfaction for } \\
\text { nursing care }\end{array}$} & \multicolumn{2}{|c|}{$\begin{array}{l}\text { Satisfaction for the } \\
\text { cleanliness of toilets }\end{array}$} \\
\hline & -4.493 & $(4.958)$ & -5.676 & $(4.497)$ & 0.273 & $(4.793)$ \\
\hline RICH $\times 2$ Years After & -1.208 & $(3.391)$ & 0.984 & $(4.034)$ & 2.218 & $(3.162)$ \\
\hline RICH $\times 3$ Years After & 0.340 & $(5.157)$ & -0.908 & $(5.068)$ & -1.478 & $(5.320)$ \\
\hline RICH $\times 4$ or More Years After & 0.272 & $(2.735)$ & 1.561 & $(3.067)$ & 2.739 & $(2.912)$ \\
\hline Within R2 & 0.20 & & 0.19 & & 0.17 & \\
\hline Nr. of observations & 135 & & 135 & & 135 & \\
\hline
\end{tabular}

\section{Appendix Table A.3. The impact of fiscal decentralization on satisfaction for medical and nursing} care and cleanliness of toilets (a)

(a) Cluster-robust standard errors at the Region level are reported in round brackets. RICH is a dummy variable equal to 1 for regions with average per-capita income above the sample mean value (treated group) and 0 for those with income below the sample mean value (control group). All models include regional and year FE. Information on health services satisfaction is available only for the years from 1998 to 2007. All estimated models consider lags of the tax reform $($ RICH $\times 1$ Year After = 1999; $R I C H \times 2$ Years After $=2000 ;$ RICH $\times 3$ Years After $=2001 ;$ RICH $\times 4$ or More Years After refers to years 2002-2007) and the effect in the year of adoption (1998) is taken as reference point.

${ }^{* * *}$ statistically significant at $1 \% ;{ }^{* *}$ statistically significant at $5 \% ;{ }^{*}$ statistically significant at $10 \%$. 


\begin{tabular}{|c|c|c|c|c|c|c|c|c|c|}
\hline \multirow{2}{*}{$\begin{array}{l}\text { Regressors } \\
G D P \times D E C E N T R\end{array}$} & MODEL 1 & \multicolumn{2}{|c|}{ MODEL 2} & \multicolumn{2}{|c|}{ MODEL 3} & \multicolumn{2}{|c|}{ MODEL 4} & \multicolumn{2}{|c|}{ MODEL 5} \\
\hline & $-2.264^{\star *} \quad(0.878)$ & - & & - & & - & & - & \\
\hline GDP $\times 3$ Years Prior & - & -3.049 & $(2.861)$ & -3.626 & $(2.845)$ & -3.521 & $(2.868)$ & -3.718 & $(2.976)$ \\
\hline GDP $\times 2$ Years Prior & - & -2.333 & $(1.971)$ & -3.060 & $(1.951)$ & -2.901 & $(1.954)$ & -3.142 & $(2.087)$ \\
\hline GDP $\times 1$ Year Prior & - & -2.272 & $(2.670)$ & -3.140 & $(2.642)$ & -3.006 & $(2.652)$ & -3.200 & $(2.771)$ \\
\hline GDP $\times$ Year of Adoption & - & -3.499 & $(2.455)$ & $-4.538^{*}$ & $(2.361)$ & $-4.337^{*}$ & $(2.357)$ & $-4.638^{*}$ & $(2.490)$ \\
\hline GDP $\times 1$ or More Years After & - & $-5.296^{*}$ & $(2.544)$ & $-4.082^{*}$ & $(2.236)$ & $-3.863^{*}$ & $(2.250)$ & $-4.232^{*}$ & $(2.406)$ \\
\hline GDP $\times 2$ or More Years After & - & - & & $-7.505^{* *}$ & $(2.578)$ & $-7.825^{* *}$ & $(2.705)$ & $-8.232^{* *}$ & $(2.893)$ \\
\hline GDP $\times 3$ or More Years After & - & - & & - & & $-6.948^{* *}$ & $(2.571)$ & $-6.718^{* *}$ & $(2.382)$ \\
\hline GDP $\times 4$ or More Years After & - & - & & - & & - & & $-7.776^{* *}$ & $(3.121)$ \\
\hline Within $\mathrm{R}^{2}$ & 0.48 & 0.49 & & 0.52 & & 0.52 & & 0.53 & \\
\hline Nr. of observations & 195 & 195 & & 195 & & 247 & & 195 & \\
\hline
\end{tabular}

Appendix Table A.4. The impact of fiscal decentralization on health inequalities considering total health spending instead of public health spending among the control variables (a)

(a) The dependent variable is the index of inequality in self-assessed health (KM). Cluster-robust standard errors at the Region level are reported in round brackets. All models include the vector of control X, regional and year FE. MODEL 2-5 extend the baseline specification to include leads $(G D P \times 1$ Year Prior $=1997, G D P \times 2$ Years Prior $=1996, G D P \times 3$ Years Prior $=1995)$ and lags $(G D P \times 1$ or More Years After refers to time period 1999-2007 in MODEL 2 and only to year 1999 in MODELS 3-5; GDP×2 or More Years After refers to time period 2000-2007 in MODEL 3 and only to year 2000 in MODELS 4-5; GDP $\times 3$ or More Years After refers to time period 2001-2007 in MODEL 4 and only to year 2001 in MODEL 5; GDP $\times 4$ or More Years After refers to time period 2002-2007). GDP $\times$ Year of Adoption refers only to the effect of decentralization observed in year 1998.

** statistically significant at $5 \%$; statistically significant at $10 \%$. 


\begin{tabular}{|c|c|c|c|c|c|c|c|c|c|c|}
\hline & \multicolumn{2}{|c|}{ High SAH } & \multicolumn{2}{|c|}{ LHA contacts } & \multicolumn{2}{|c|}{ Home care } & \multicolumn{2}{|c|}{ Emergency care } & \multicolumn{2}{|c|}{ Inpatient care } \\
\hline $\begin{array}{l}G D P \times D E C E N T R \\
\text { Pseudo } \mathrm{R}^{2} \\
\text { Nr. of observations }\end{array}$ & $\begin{array}{l}1.004 \\
0.18 \\
258,767\end{array}$ & (1.133) & $\begin{array}{l}2.499^{* *} \\
0.07 \\
246,471\end{array}$ & (1.036) & \begin{tabular}{|l}
-1.955 \\
0.14 \\
287,163
\end{tabular} & $(2.250)$ & $\begin{array}{l}-11.402^{* * *} \\
0.06 \\
289,914\end{array}$ & (1.378) & $\begin{array}{l}-2.762^{*} \\
0.11 \\
290,618\end{array}$ & (1.620) \\
\hline $\begin{array}{l}\text { MEDIUM EDU } \\
G D P \times D E C E N T R \\
\text { Pseudo R }{ }^{2} \\
\text { Nr. of observations }\end{array}$ & $\begin{array}{l}3.645^{* *} \\
0.10 \\
142,482\end{array}$ & (1.798) & $\begin{array}{l}7.108^{* * *} \\
0.08 \\
139,688\end{array}$ & (1.413) & $\begin{array}{l}9.768^{* *} \\
0.11 \\
140,434\end{array}$ & (3.730) & $\begin{array}{c}-13.138^{* * *} \\
0.06 \\
141,555\end{array}$ & (2.167) & $\begin{array}{l}-2.390^{*} \\
0.09 \\
141,845\end{array}$ & (1.413) \\
\hline $\begin{array}{l}\text { HIGH EDU } \\
G D P \times D E C E N T R \\
\text { Pseudo R2 } \\
\text { Nr. of observations }\end{array}$ & $\begin{array}{l}-4.166 \\
0.09 \\
33,773\end{array}$ & (3.729) & $\begin{array}{l}3.953 \\
0.06 \\
33,048\end{array}$ & (2.945) & $\begin{array}{l}2.950 \\
0.10 \\
33,269\end{array}$ & (7.776) & $\begin{array}{l}-9.342^{* *} \\
0.05 \\
33,523\end{array}$ & (4.684) & \begin{tabular}{|l|}
1.327 \\
0.10 \\
33,584
\end{tabular} & (5.530) \\
\hline
\end{tabular}

\section{Appendix Table A.5. The impact of fiscal decentralization on individual SAH and healthcare services utilization by education level (a)}

(a) Probit estimates, robust standard errors in round brackets. High SAH is a dummy variable equal to 1 if the individual reported a good (4) or very good (5) health status; LHA contacts is a dummy variable equal to 1 if the individual had contacts with the Local Health Authority to schedule appointments for outpatient visits, blood tests or other laboratory tests during the year of the interview; Home care, Emergency care and Inpatient care are analogous dummies indicating whether or not the respondent utilized home care, emergency care and inpatient care services. LOW EDU is the sub-sample of individuals with no educational certificates or primary school certificate or lower secondary education; MEDIUM EDU is the sub-sample of individuals with upper secondary education or high school graduation; HIGH EDU is the sub-sample of individuals with university or postgraduate degree. All models include among the covariates socio-demographic characteristics (age, gender, marital status) and enabling/disabling factors (employment status, wealth, private health insurance, difficulties in accessing healthcare services due to distance, monetary costs, or waiting times); when using High SAH as dependent variable, the set of regressors also includes lifestyle indicators (smoking, diet); when using healthcare access indicators as dependent variables, the models also account for individuals' health status (self-assessed health, health conditions).

${ }^{* * *}$ statistically significant at $1 \% ;{ }^{* *}$ statistically significant at $5 \% ;{ }^{*}$ statistically significant at $10 \%$. 

1. L. Colombo, H. Dawid, Strategic Location Choice under Dynamic Oligopolistic Competition and Spillovers, novembre 2013.

2. M. Bordignon, M. Gamalerio, G. Turati, Decentralization, Vertical Fiscal Imbalance, and Political Selection, novembre 2013.

3. M. Guerini, Is the Friedman Rule Stabilizing? Some Unpleasant Results in a Heterogeneous Expectations Framework, novembre 2013.

4. E. Brenna, C. Di Novi, Is caring for elderly parents detrimental to women's mental health? The influence of the European North-South gradient, novembre 2013.

5. F. Sobbrio, Citizen-Editors' Endogenous Information Acquisition and News Accuracy, novembre 2013.

6. P. Bingley, L. Cappellari, Correlation of Brothers Earnings and Intergenerational Transmission, novembre 2013.

7. T. Assenza, W. A. Brock, C. H. Hommes, Animal Spirits, Heterogeneous Expectations and the Emergence of Booms and Busts, dicembre 2013.

8. D. Parisi, Is There Room for 'Fear' as a Human Passion in the Work by Adam Smith?, gennaio 2014.

9. E. Brenna, F. Spandonaro, Does federalism induce patients' mobility across regions? Evidence from the Italian experience, febbraio 2014.

10. A. Monticini, F. Ravazzolo, Forecasting the intraday market price of money, febbraio 2014.

11. Tiziana Assenza, Jakob Grazzini, Cars Hommes, Domenico Massaro, PQ Strategies in Monopolistic Competition: Some Insights from the Lab, marzo 2014.

12. R. Davidson, A. Monticini, Heteroskedasticity-and-Autocorrelation-Consistent Bootstrapping, marzo 2014.

13. C. Lucifora, S. Moriconi, Policy Myopia and Labour Market Institutions, giugno 2014.

14. N. Pecora, A. Spelta, Shareholding Network in the Euro Area Banking Market, giugno 2014.

15. G. Mazzolini, The economic consequences of accidents at work, giugno 2014.

16. M. Ambrosanio, P. Balduzzi, M. Bordignon, Economic crisis and fiscal federalism in Italy, settembre 2014.

17. P. Bingley, L. Cappellari, K. Tatsiramos, Family, Community and Long-Term Earnings Inequality, ottobre 2014.

18. S. Frazzoni, M. L. Mancusi, Z. Rotondi, M. Sobrero, A. Vezzulli, Innovation and export in SMEs: the role of relationship banking, novembre 2014.

19. H. Gnutzmann, Price Discrimination in Asymmetric Industries: Implications for Competition and Welfare, novembre 2014.

20. A. Baglioni, A. Boitani, M. Bordignon, Labor mobility and fiscal policy in a currency union, novembre 2014.

21. C. Nielsen, Rational Overconfidence and Social Security, dicembre 2014.

22. M. Kurz, M. Motolese, G. Piccillo, H. Wu, Monetary Policy with Diverse Private Expectations, febbraio 2015.

23. S. Piccolo, P. Tedeschi, G. Ursino, How Limiting Deceptive Practices Harms Consumers, maggio 2015.

24. A.K.S. Chand, S. Currarini, G. Ursino, Cheap Talk with Correlated Signals, maggio 2015.

25. S. Piccolo, P. Tedeschi, G. Ursino, Deceptive Advertising with Rational Buyers, giugno 2015. 
26. S. Piccolo, E. Tarantino, G. Ursino, The Value of Transparency in Multidivisional Firms, giugno 2015.

27. G. Ursino, Supply Chain Control: a Theory of Vertical Integration, giugno 2015.

28. I. Aldasoro, D. Delli Gatti, E. Faia, Bank Networks: Contagion, Systemic Risk and Prudential Policy, luglio 2015.

29. S. Moriconi, G. Peri, Country-Specific Preferences and Employment Rates in Europe, settembre 2015.

30. R. Crinò, L. Ogliari, Financial Frictions, Product Quality, and International Trade, settembre 2015.

31. J. Grazzini, A. Spelta, An empirical analysis of the global input-output network and its evolution, ottobre 2015.

32. L. Cappellari, A. Di Paolo, Bilingual Schooling and Earnings: Evidence from a Languagein-Education Reform, novembre 2015.

33. A. Litina, S. Moriconi, S. Zanaj, The Cultural Transmission of Environmental Preferences: Evidence from International Migration, novembre 2015.

34. S. Moriconi, P. M. Picard, S. Zanaj, Commodity Taxation and Regulatory Competition, novembre 2015.

35. M. Bordignon, V. Grembi, S. Piazza, Who do you blame in local finance? An analysis of municipal financing in Italy, dicembre 2015.

36. A. Spelta, A unified view of systemic risk: detecting SIFIs and forecasting the financial cycle via EWSs, gennaio 2016.

37. N. Pecora, A. Spelta, Discovering SIFIs in interbank communities, febbraio 2016.

38. M. Botta, L. Colombo, Macroeconomic and Institutional Determinants of Capital Structure Decisions, aprile 2016.

39. A. Gamba, G. Immordino, S. Piccolo, Organized Crime and the Bright Side of Subversion of Law, maggio 2016.

40. L. Corno, N. Hildebrandt, A. Voena, Weather Shocks, Age of Marriage and the Direction of Marriage Payments, maggio 2016.

41. A. Spelta, Stock prices prediction via tensor decomposition and links forecast, maggio 2016.

42. T. Assenza, D. Delli Gatti, J. Grazzini, G. Ricchiuti, Heterogeneous Firms and International Trade: The role of productivity and financial fragility, giugno 2016.

43. S. Moriconi, Taxation, industry integration and production efficiency, giugno 2016.

44. L. Fiorito, C. Orsi, Survival Value and a Robust, Practical, Joyless Individualism: Thomas Nixon Carver, Social Justice, and Eugenics, luglio 2016.

45. E. Cottini, P. Ghinetti, Employment insecurity and employees' health in Denmark, settembre 2016.

46. G. Cecere, N. Corrocher, M. L. Mancusi, Financial constraints and public funding for ecoinnovation: Empirical evidence on European SMEs, settembre 2016.

47. E. Brenna, L. Gitto, Financing elderly care in Italy and Europe. Is there a common vision?, settembre 2016.

48. D. G. C. Britto, Unemployment Insurance and the Duration of Employment: Theory and Evidence from a Regression Kink Design, settembre 2016.

49. E. Caroli, C.Lucifora, D. Vigani, Is there a Retirement-Health Care utilization puzzle? Evidence from SHARE data in Europe, ottobre 2016.

50. G. Femminis, From simple growth to numerical simulations: A primer in dynamic programming, ottobre 2016.

51. C. Lucifora, M. Tonello, Monitoring and sanctioning cheating at school: What works? Evidence from a national evaluation program, ottobre 2016. 
52. A. Baglioni, M. Esposito, Modigliani-Miller Doesn't Hold in a "Bailinable" World: A New Capital Structure to Reduce the Banks' Funding Cost, novembre 2016.

53. L. Cappellari, P. Castelnovo, D. Checchi, M. Leonardi, Skilled or educated? Educational reforms, human capital and earnings, novembre 2016.

54. D. Britto, S. Fiorin, Corruption and Legislature Size: Evidence from Brazil, dicembre 2016.

55. F. Andreoli, E. Peluso, So close yet so unequal: Reconsidering spatial inequality in U.S. cities, febbraio 2017.

56. E. Cottini, P. Ghinetti, Is it the way you live or the job you have? Health effects of lifestyles and working conditions, marzo 2017.

57. A. Albanese, L. Cappellari, M. Leonardi, The Effects of Youth Labor Market Reforms: Evidence from Italian Apprenticeships; maggio 2017.

58. S. Perdichizzi, Estimating Fiscal multipliers in the Eurozone. A Nonlinear Panel Data Approach, maggio 2017.

59. S. Perdichizzi, The impact of ECBs conventional and unconventional monetary policies on European banking indexes returns, maggio 2017.

60. E. Brenna, Healthcare tax credits: financial help to taxpayers or support to higher income and better educated patients? Evidence from Italy, giugno 2017.

61. G. Gokmen, T. Nannicini, M. G. Onorato, C. Papageorgiou, Policies in Hard Times: Assessing the Impact of Financial Crises on Structural Reforms, settembre 2017.

62. M. Tettamanzi, E Many Pluribus Unum: A Behavioural Macro-Economic Agent Based Model, novembre 2017.

63. A. Boitani, C. Punzo, Banks' leverage behaviour in a two-agent New Keynesian model, gennaio 2018.

64. M. Bertoni, G. Brunello, L. Cappellari, Parents, Siblings and Schoolmates. The Effects of Family-School Interactions on Educational Achievement and Long-term Labor Market Outcomes, gennaio 2018.

65. G. P. Barbetta, G. Sorrenti, G. Turati, Multigrading and Child Achievement, gennaio 2018.

66. S. Gagliarducci, M. G. Onorato, F. Sobbrio, G. Tabellini, War of the Waves: Radio and Resistance During World War II, febbraio 2018.

67. P. Bingley, L. Cappellari, Workers, Firms and Life-Cycle Wage Dynamics, marzo 2018.

68. A. Boitani, S. Perdichizzi, Public Expenditure Multipliers in recessions. Evidence from the Eurozone, marzo 2018.

69. M. Le Moglie, G. Turati, Electoral Cycle Bias in the Media Coverage of Corruption News, aprile 2018.

70. R. Davidson, A. Monticini, Improvements in Bootstrap Inference, aprile 2018.

71. R. Crinò, G. Immordino, S. Piccolo, Fighting Mobile Crime, giugno 2018.

72. R. Caminal, L. Cappellari, A. Di Paolo, Linguistic skills and the intergenerational transmission of language, agosto 2018.

73. E. Brenna, L. Gitto, Adult education, the use of Information and Communication Technologies and the impact on quality of life: a case study, settembre 2018.

74. M. Bordignon, Y. Deng, J. Huang, J. Yang, Plunging into the Sea: Ideological Change, Institutional Environments and Private Entrepreneurship in China, settembre 2018.

75. M. Bordignon, D. Xiang, L. Zhan, Predicting the Effects of a Sugar Sweetened Beverage Tax in a Household Production Model, settembre 2018.

76. C. Punzo, L. Rossi, The Redistributive Effects of a Money-Financed Fiscal Stimulus, gennaio 2019.

77. A. Baglioni, L. Colombo, P. Rossi, Debt restructuring with multiple bank relationships, gennaio 2019. 
78. E. Cottini, P. Ghinetti, S. Moriconi, Higher Education Supply, Neighbourhood effects and Economic Welfare, febbraio 2019.

79. S. Della Lena, F. Panebianco, Cultural Transmission with Incomplete Information: Parental Perceived Efficacy and Group Misrepresentation, marzo 2019.

80. T. Colussi, Ingo E. Isphording, Nico Pestel, Minority Salience and Political Extremism, marzo 2019.

81. G. P. Barbetta, P. Canino, S. Cima, Let's tweet again? The impact of social networks on literature achievement in high school students: Evidence from a randomized controlled trial, maggio 2019.

82. Y. Brilli, C. Lucifora, A. Russo, M. Tonello, Vaccination take-up and health: evidence from a flu vaccination program for the elderly, giugno 2019.

83. C. Di Novi, M. Piacenza, S. Robone, G. Turati, Does fiscal decentralization affect regional disparities in health? Quasi-experimental evidence from Italy, luglio 2019. 